\title{
Coral reproduction in Western Australia
}

James Gilmour, Conrad W Speed, Russ Babcock

Larval production and recruitment underpin the maintenance of coral populations, but these early life history stages are vulnerable to extreme variation in physical conditions. Environmental managers aim to minimise human impacts during significant periods of larval production and recruitment on reefs, but doing so requires knowledge of the modes and timing of coral reproduction. Most corals are hermaphroditic or gonochoric, with a brooding or broadcast spawning mode of reproduction. Brooding corals are a significant component of some reefs and produce larvae over consecutive months. Broadcast spawning corals are more common and display considerable variation in their patterns of spawning among reefs. Highly synchronous spawning can occur on reefs around Australia, particularly on the Great Barrier Reef. On Australia's remote north-west coast there have been fewer studies of coral reproduction. The recent industrial expansion into these regions has facilitated research, but the associated data are often contained within confidential reports. Here we combine information in this grey-literature with that available publicly to update our knowledge of coral reproduction in WA, for tens of thousands of corals and hundreds of species from over a dozen reefs spanning 20 degrees of latitude. We identified broad patterns in coral reproduction, but more detailed insights were hindered by biased sampling; most studies focused on species of Acropora sampled over a few months at several reefs. Within the existing data, there was a latitudinal gradient in spawning activity among seasons, with mass spawning during autumn occurring on all reefs (but the temperate south-west). Participation in a smaller, multi-specific spawning during spring decreased from approximately one quarter of corals on the Kimberley Oceanic reefs to little participation at Ningaloo. Within these seasons, spawning was concentrated in March and/or April, and October and/or November, depending on the timing of the full moon. The timing of the full moon determined whether spawning was split over two months, which was common on tropical reefs. There were few data available for non-Acropora corals, which may have different patterns of reproduction. For example, the massive Porites seemed to spawn through spring to autumn on Kimberley Oceanic reefs and during summer in the Pilbara region, where other common corals (e.g. Turbinaria \& Pavona) also displayed different patterns of reproduction to the Acropora. The brooding corals (Isopora \& Seriatopora) on Kimberley Oceanic reefs appeared to planulate during 
many months, possibly with peaks from spring to autumn; a similar pattern is likely on other WA reefs. Gaps in knowledge were also due to the difficulty in identifying species and issues with methodology. We briefly discuss some of these issues and suggest an approach to quantifying variation in reproductive output throughout a year. 


\section{Coral reproduction in Western Australia}

\section{James Gilmour ${ }^{1,3 *}$, Conrad Speed ${ }^{1,3}$, Russ Babcock ${ }^{2,3}$}

$3{ }^{1}$ Australian Institute of Marine Science, The UWA Oceans Institute, Crawley, Western Australia, 4 Australia.

$5 \quad{ }^{2}$ Commonwealth Scientific and Industrial Research Organisation, Oceans and Atmosphere, GPO

62583 Brisbane 4001, Queensland, Australia.

$7 \quad{ }^{3}$ Western Australian Marine Science Institution, Western Australia, Australia.

8 *Corresponding author

\section{ABSTRACT}

Larval production and recruitment underpin the maintenance of coral populations, but these early life history stages are vulnerable to extreme variation in physical conditions.

Environmental managers aim to minimise human impacts during significant periods of larval production and recruitment on reefs, but doing so requires knowledge of the modes and timing of coral reproduction. Most corals are hermaphroditic or gonochoric, with a brooding or broadcast spawning mode of reproduction. Brooding corals are a significant component of some reefs and produce larvae over consecutive months. Broadcast spawning corals are more common and display considerable variation in their patterns of spawning among reefs. Highly synchronous spawning can occur on reefs around Australia, particularly on the Great Barrier Reef. On Australia's remote north-west coast there have been fewer studies of coral reproduction. The recent industrial expansion into these regions has facilitated research, but the associated data are often contained within confidential reports. Here we combine information in this grey-literature with that available publicly to update our knowledge of coral reproduction in WA, for tens of thousands of corals and hundreds of species from over a dozen reefs spanning 20 degrees of latitude. We identified broad patterns in coral reproduction, but more detailed insights were hindered by biased sampling; most studies focused on species of Acropora sampled over a few months at several reefs. Within the existing data, there was a latitudinal gradient in spawning 
activity among seasons, with mass spawning during autumn occurring on all reefs (but the temperate south-west). Participation in a smaller, multi-specific spawning during spring decreased from approximately one quarter of corals on the Kimberley Oceanic reefs to little participation at Ningaloo. Within these seasons, spawning was concentrated in March and/or April, and October and/or November, depending on the timing of the full moon. The timing of the full moon determined whether spawning was split over two months, which was common on tropical reefs. There were few data available for non-Acropora corals, which may have different patterns of reproduction. For example, the massive Porites seemed to spawn through spring to autumn on Kimberley Oceanic reefs and during summer in the Pilbara region, where other common corals (e.g. Turbinaria \& Pavona) also displayed different patterns of reproduction to the Acropora. The brooding corals (Isopora \& Seriatopora) on Kimberley Oceanic reefs appeared to planulate during many months, possibly with peaks from spring to autumn; a similar pattern is likely on other WA reefs. Gaps in knowledge were also due to the difficulty in identifying species and issues with methodology. We briefly discuss some of these issues and suggest an approach to quantifying variation in reproductive output throughout a year.

\section{INTRODUCTION}

\section{Reproduction in scleractinian corals}

Sexual recruitment underpins the maintenance of most coral communities, so knowing their peak times of reproductive output is critical to the management of human activities that reduce recruitment to the adult population. Larval production, recruitment, and early post-recruitment survival in corals are reduced by extreme variation in physical factors such as temperature and salinity (Bassim et al. 2000; Harrison et al. 1990; Harrison 2011; Negri et al. 2007) or degraded water quality (Gilmour 1999; Harrison \& Ward 2001; Humphrey et al. 2008; Markey et al. 2007; Negri \& Heyward 2001). Model projections highlight the implications of prolonged reductions in larval recruitment for the maintenance of coral populations, and particularly their recovery following disturbances (Babcock 1991; Done 1987; Edmunds 2005; Fong \& Glynn 2000; Gilmour et al. 2006; Smith et al. 2005). The times of reproduction also influence the community recovery via connectivity to other coral reefs (Gilmour, 2009, Done, 2015). For example, the 
58 larvae of brooding corals are released several times a year under a range of hydrodynamic 59 conditions, but typically disperse over relatively short distances ( $<$ several kilometres), whereas

60 the larvae of spawning corals are produced during one or a few discrete periods, and disperse over larger distances ( $>$ several kilometres). A detailed understanding of community reproduction is therefore required to mitigate human activities around critical periods of larval production and to inform the design of management networks reliant on estimates of larval exchange (Carson \& al 2010; Kool et al. 2013).

Most scleractinian corals have one of four patterns of sexual reproduction, depending on their sexuality (hermaphroditic or gonochoric) and developmental mode (brooding or broadcast spawning) (Baird et al. 2009; Fadlallah 1983; Harrison et al. 1990; Harrison 2011; Richmond \& Hunter 1990). In brooding corals, the fertilisation of eggs and subsequent development of larvae occur within the parental polyps. Larvae are competent to settle shortly after their release from the polyp, with planulation typically occurring over several months each year. In contrast, colonies of broadcast spawning corals typically release their gametes into the water column once a year, where fertilization and larval development occur, after which larvae disperse for days to weeks before settling. Some coral species (or cryptic sub-species) have more complex patterns of reproduction (e.g. Pocillopora damicornis), while blurred species boundaries and flexible breeding systems continue to confound our understanding of reproduction in many coral taxa (van Oppen et al. 2002; Veron 2011; Willis 1990; Willis et al. 2006).

Reproductive activity in spawning corals can be remarkably synchronised, culminating in the release of gametes by a high proportion of species and colonies during a few nights each year (mass spawning), or spawning by a similar proportion of colonies and species may be protracted over many nights and several months (Baird et al. 2009; Harrison et al. 1990; Harrison 2011). The ultimate factor driving high synchrony, particularly within species, is probably successful fertilisation and larval recruitment. However, a wide range of environmental factors underlie this success and cue spawning over increasingly fine temporal scales, such as water temperature, day length, moon phases and tidal amplitude (Baird et al. 2009; Guest et al. 2005a; Harrison et al. 1990; Penland et al. 2004; van Woesik 2010). These cues all interact to synchronise spawning within communities, so it is tempting to view mass spawning as a phenomenon that occurs at the community level, whereas each species is in fact responding independently to its environment. As conditions vary, gametogenic cycles in each species will respond differently, as their 
89

90

91

environmental optima may differ or because the environment provides fewer synchronising cues (Oliver et al. 1988). Indeed, environmental stress will reduce the energy available for gametogenesis and the likelihood of corals reproducing during a given year (Michalek-Wagner \& Willis 2001; Ward et al. 2000), also confounding generalities about spawning patterns. The species composition of reefs changes as environmental conditions vary, further influencing the patterns of reproduction at the reef scale. Clearly there is significant scope for reproduction of coral assemblages on reefs to vary regionally and depart from the 'mass spawning' discovered on the Great Barrier Reef (Babcock et al. 1986; Harrison et al. 1984) and subsequently pursued by some investigations of coral reproduction around the world. This variation in timing and synchrony results in a range of reproductive patterns, from temporal isolation of spawning species to a highly synchronous mass-spawning.

Mass spawning in scleractinian corals was first discovered on parts of the GBR in austral spring (Harrison et al. 1984; Willis et al. 1985), where it is perhaps more synchronous than on any other coral reef worldwide. However, even on the GBR there is a spatial and temporal variation in mass-spawning. For example, the near-shore reefs spawn one month earlier than those on midand outer-shelf reefs (Willis et al. 1985), while the high- and low-latitude reefs have a more protracted period of spawning at times other than during spring (Baird et al. 2009; Baird et al. 2002; Harrison 2008; Oliver et al. 1988; Wilson \& Harrison 2003). Additionally, spawning times within coral assemblages also vary among years according to the timing of the full moon within the spawning window. The date of the full moon occurs several days earlier each month than in the previous year, causing spawning times to shift periodically (e.g. from October to November) if gametes are not yet mature at the time of full moon. Similarly, when the full moon falls near the edge of the spawning window then only some colonies will have mature gametes, so spawning occurs following two consecutive full moons (e.g. October and November). This phenomenon has been termed 'split spawning' and typically occurs every few years, but can occasionally occur over consecutive years (Baird et al. 2009; Willis 1985).

Many of the early studies leading to the discovery of mass spawning on the GBR involved rigorous sampling of colonies using a range of methods throughout the year, which established synchronous reproductive cycles within and among populations (Wallace 1985). This led to more intensive sampling over weeks and days, which established the remarkable synchrony among many colonies and species over a few nights each year. In contrast, some subsequent 
120 studies have focused on identifying the species participating in mass spawning events but not

121 quantifying the proportion of participating colonies or the frequency of spawning during other

122 times (nights, weeks, months, and seasons) of the year. Without estimates of the reproductive

123 state of colonies during other times of the year, a relative assessment of the participation in mass

124 spawning events is not possible; if there is a low participation in the mass spawning then there is

125 no knowledge of the other time(s) of spawning, whereas if there is a moderate to high

126 participation then it may be assumed incorrectly that spawning during the other time(s) is

127 negligible. For example, a rigorous sampling of the reproductive state of coral populations

128 throughout the year has identified a second spawning by populations and even some colonies on

129 the GBR (Stobart et al. 1992; Wolstenholme 2004) and other reefs around the world (Dai et al.

130 2000; Guest et al. 2005b; Mangubhai 2009; Mangubhai \& Harrison 2006; Oliver et al. 1988).

131 Focussing only on the participation of corals in the mass spawning can also miss the times of

132 reproduction for entire species that are common and functionally important, such as the massive

133 Porites (Harriott 1983a; Kojis \& Quinn 1982). Additionally, brooding corals are a significant

134 component of many reefs, and planulation in populations and colonies is typically spread over

135 several months throughout the year (Ayre \& Resing 1986; Harriott 1992; Harrison et al. 1990;

136 Harrison 2011; Tanner 1996).

137 Despite considerable research effort on the GBR, there is still not a detailed understanding of

138 spatial and temporal variation in coral reproduction at the scale of entire assemblages. This

139 highlights the difficulty in obtaining a similar understanding for the remote coral reefs on

140 Australia's west coast, where far less research has been conducted. Most studies of coral

141 reproduction in Western Australia (WA) have been conducted over a few months at several

142 reefs, of which there are few published accounts (but see Supplementary Table 1), leaving large

143 gaps in knowledge. The gaps are significant because the existing data illustrate the unique

144 patterns of reproduction displayed by WA coral communities and the extent to which they vary

145 among habitats and regions. The rapid industrial expansion through regions of WA in the last

146 decade has seen an increase in the number of studies of coral reproduction, but much of the

147 associated data are contained within confidential reports to industry and government. Here we

148 combine some of the information in this grey-literature with that in public reports and papers, to

149 update our current knowledge of coral reproduction in WA. This includes data for tens of

150 thousands of corals and hundreds of species, from over a dozen reefs spanning 20 degrees of 
151 latitude. From these data we identify broad latitudinal patterns, but many gaps in knowledge

152 remain due to paucity of data, biased sampling, and in some instances poor application of 153 methodology. We therefore conclude with a brief discussion around issues of sampling design

154 and methodology, and suggest one approach to quantifying the significance of periods of

155 reproductive output by coral communities, which is among the suite of information required by 156 managers to moderate the effects of human activities along Australia's west coast.

157

158

159

160

161

162

163

164

165

166

167

168

169

170

171

172

173

174

175

176

177

178

179

\section{METHODS}

\section{Western Australian regions and sources of reproductive data}

Western Australia's coral reefs span more than $12,000 \mathrm{~km}$ of coastline and $20^{\circ}$ of latitude, ranging from tropical to temperate climates, from coastal reefs to oceanic atolls hundreds of kilometres from the mainland (Veron \& Marsh 1988; Wilson 2013). Consequently, WA has a phenomenal diversity of habitats and coral communities, with a corresponding range in reeflevel patterns of coral reproduction. Because of these broad patterns in coral community composition, the examination of patterns of reproduction presented here is divided among six regions: (1) Kimberley Oceanic, (2) Kimberley, (3) Pilbara, (4) Ningaloo, (5) Abrolhos and Shark Bay, and (6) Rottnest and southwest WA (Figure 1). Among these regions, the diversity of coral species and genera decreases with increasing latitude (Figure 1), although coral cover can be similar among the tropical reefs and those at the subtropical Abrolhos Islands, before then decreasing in the temperate southwest (Abdo et al. 2012; Johannes et al. 1983; McKinney 2009; Richards \& Rosser 2012; Richards et al. 2014; Speed et al. 2013; Veron \& Marsh 1988).

Regional data or data summaries of coral reproduction were taken from journal articles and public reports, unpublished data, and confidential reports to industry and government

(Supplementary Table 1). Where possible, raw data were interrogated and summaries produced across reefs for each region. However, in other instances raw data were not available and regional summaries were based on tables and text within reports that had not been peerreviewed. Given the scope of these data, discrepancies also existed among studies and there are likely errors in data collection, analyses and species identification. Some regional summaries were adjusted to account for obvious errors in data or conclusions in some reports and the most 
180 likely patterns of reproduction were sometimes extrapolated from limited data. Additionally,

181 samples were typically biased by factors such as the environmental conditions, the community

182 composition, the sampling design and the methods used. For example, inferences about the

183 patterns of reproduction on a reef were heavily biased when: data exist for a few species of

184 Acropora but the community was dominated by non-Acropora corals that reproduce at different

185 times; environmental stress inhibited gametogenesis causing a large portion of the assemblage

186 not to reproduce in a period; spawning was split over two consecutive months but only one

187 month was sampled; coral species and/or genera were incorrectly identified. The issues were

188 most acute in studies with limited spatial and temporal replication. For these reasons, a summary

189 of information that commonly biases inferences about patterns of coral reproduction is presented

190 for each region, to place in context the reproductive data, and times of spawning for species were

191 assigned a level of confidence according to the available data (Table 1, Table 2, and

192 Supplementary Table 2).

193 Coral reef habitats of WA are characterised by widely contrasting environments, but all are

194 exposed to considerable wave energy generated by seasonal cyclones and/or storms. Reef

195 habitats range from open ocean atolls surrounded by deep oligotrophic waters in the Kimberley

196 Oceanic Region, to reefs heavily influenced by coastal processes such as tidally driven sediment

197 resuspension in the inshore Kimberley and Pilbara Regions. From the coastal fringing reefs of

198 Ningaloo, to the subtropical and temperate reefs at the Abrolhos Island and the Southwest

199 Region, tidal processes are less extreme, waters are clearer and often lower in nutrients. This is

200 due in part to the southward flowing Leeuwin Current which intensifies in winter, moderating

201 winter temperature minima and assisting the transport of coral larvae to southern reefs

202 (Cresswell 1996; D’Adamo et al. 2009; Hatcher 1991). Consequently, there is a high level of

203 reef development in the sub-tropical reefs at the Abrolhos Islands. While the low latitude reefs in

204 the Kimberley have the highest species diversity, they also experience the most pronounced

205 differences in environmental conditions and community composition between the oceanic reefs

206 and those adjacent to the mainland (Richards et al. 2015; Richards et al. 2014). Similarly, within

207 the Pilbara Region, community composition differs between the most frequently studied inshore

208 reefs in the Dampier Archipelago where most reproductive data exist, and mid-shelf around

209 Barrow and Montebello islands (Richards \& Rosser 2012; Richards et al. 2014). More

210 information about the environmental characteristics and the context for reef development and 
211 coral reproduction in each region is provided in the Supplementary text. Preceding the

212 reproductive summary for reefs within each region is information to place these data in context,

213 which includes: the species diversity and community composition of corals; the number and

214 types of reefs, sites and species for which reproductive data were collected and the time(s) of

215 sampling; whether colonies were affected by disturbances at the times of sampling; and the

216 methods used to infer the times of spawning or planulae release.

Figure 1. Regions in which the composition of coral reefs and the proposed patterns of coral reproduction differ most significantly across Western Australia. Numbers in brackets indicate the number of coral genera identified in each region (see Table 1).

Red circles indicate reefs at which data on coral reproduction were available, from which inferences about the differences among regions were drawn.

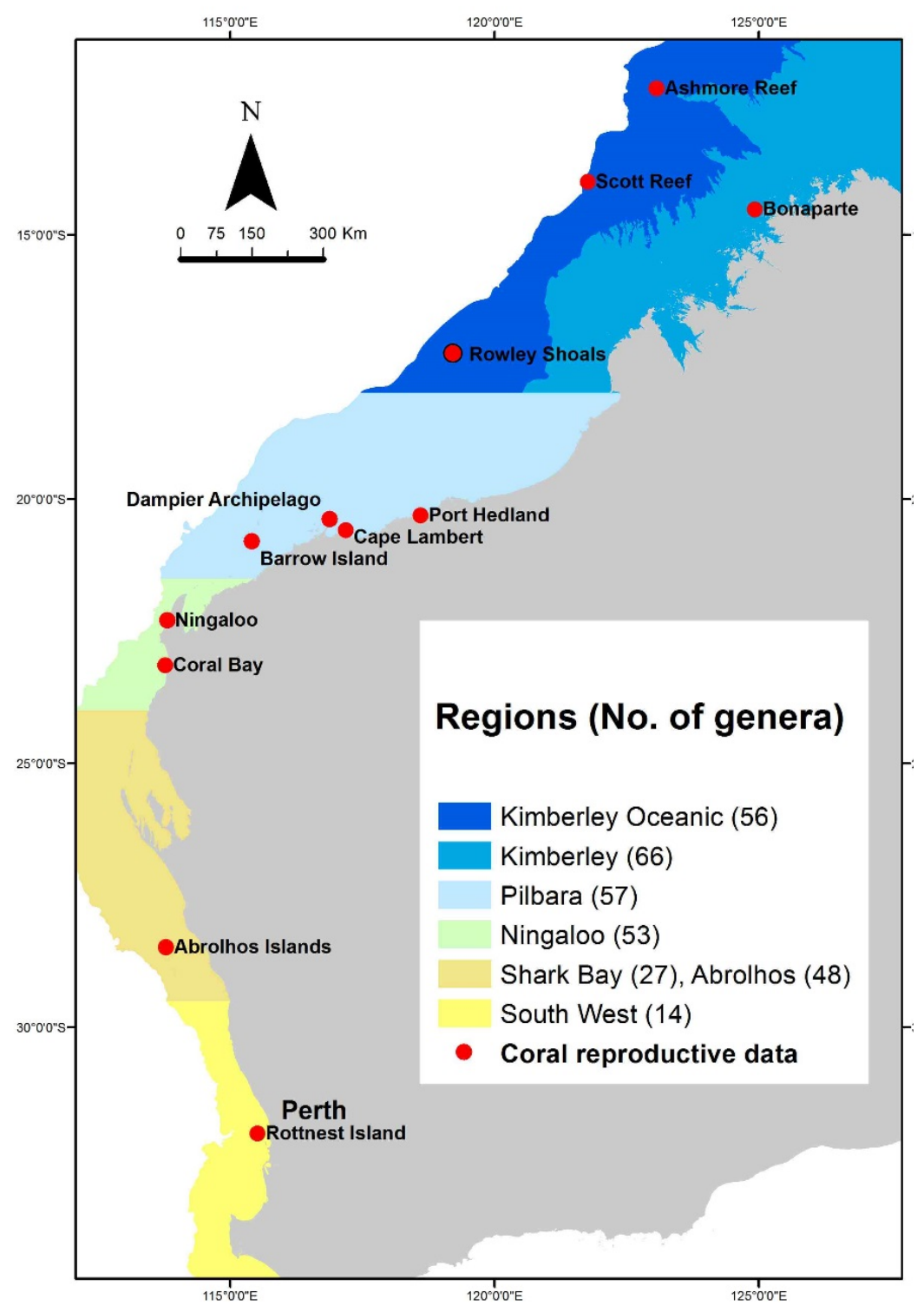


Table 1. Regional variation in coral diversity and reproduction across Western Australia. The number of species within each coral genus know to occur within each region of WA, and the number for which reproductive data are available. The percentage of species within each genus known to reproduce in spring or autumn within each region, of the total sampled. Regions are colour coded according to Figure 1. Dashes lines indicate no data for that genus. Diversity data are summarised from several key references (Berry 1993; Berry \& Marsh 1986; Done et al. 1994; Richards et al. 2015; Richards \& Rosser 2012; Richards et al. 2009; Richards et al. 2014; Veron 1993; Veron \& Marsh 1988).

\begin{tabular}{|c|c|c|c|c|c|c|}
\hline \multirow{2}{*}{ Region } & \multirow{2}{*}{ Genus } & \multirow{2}{*}{$\begin{array}{c}\text { Total known } \\
\text { species }\end{array}$} & \multicolumn{2}{|c|}{ Number of species sampled } & \multicolumn{2}{|c|}{ Spawning \% (number) of species } \\
\hline & & & Spring & Autumn & Spring & Autumn \\
\hline \multirow{10}{*}{$\begin{array}{l}\text { Kimberley } \\
\text { Oceanic }\end{array}$} & Acropora & 63 & 39 & 49 & $90(35)$ & $94(46)$ \\
\hline & Echinophyllia & 3 & 1 & 2 & $0(0)$ & $100(2)$ \\
\hline & Favia & 13 & 4 & 6 & $75(3)$ & $100(6)$ \\
\hline & Favites & 8 & 3 & 3 & $33(1)$ & $100(3)$ \\
\hline & Goniastrea & 6 & 2 & 6 & $100(2)$ & $100(6)$ \\
\hline & Hydnophora & 4 & 2 & 1 & $50(1)$ & $100(1)$ \\
\hline & Lobophyllia & 3 & 1 & 0 & $100(1)$ & - \\
\hline & Merulina & 2 & 2 & 2 & $0(0)$ & $100(2)$ \\
\hline & Montipora & 28 & 0 & 0 & - & - \\
\hline & Platygyra & 6 & 0 & 3 & - & $100(3)$ \\
\hline \multirow{10}{*}{ Kimberley } & Acropora & 39 & 35 & 16 & $42(15)$ & $87(14)$ \\
\hline & Echinophyllia & 3 & 0 & 0 & - & - \\
\hline & Favia & 9 & 2 & 1 & $0(0)$ & $100(1)$ \\
\hline & Favites & 6 & 2 & 1 & $0(0)$ & $100(1)$ \\
\hline & Goniastrea & 7 & 4 & 1 & $0(0)$ & $100(1)$ \\
\hline & Hydnophora & 4 & 4 & 0 & $75(3)$ & - \\
\hline & Lobophyllia & 2 & 2 & 0 & $0(0)$ & - \\
\hline & Merulina & 1 & 1 & 0 & $0(0)$ & - \\
\hline & Montipora & 23 & 0 & 0 & - & - \\
\hline & Platygyra & 5 & 3 & 1 & $0(0)$ & $100(1)$ \\
\hline \multirow{10}{*}{ Pilbara } & Acropora & 49 & 35 & 43 & $34(12)$ & $98(42)$ \\
\hline & Echinophyllia & 2 & 0 & 0 & - & - \\
\hline & Favia & 10 & 1 & 8 & $0(0)$ & $87(7)$ \\
\hline & Favites & 7 & 2 & 4 & $50(1)$ & $100(4)$ \\
\hline & Goniastrea & 7 & 5 & 7 & $0(0)$ & $100(7)$ \\
\hline & Hydnophora & 4 & 1 & 1 & $0(0)$ & $100(1)$ \\
\hline & Lobophyllia & 3 & 1 & 2 & $0(0)$ & $100(2)$ \\
\hline & Merulina & 2 & 1 & 1 & $0(0)$ & $100(1)$ \\
\hline & Montipora & 28 & 4 & 3 & $0(0)$ & $66(2)$ \\
\hline & Platygyra & 6 & 4 & 6 & $0(0)$ & $100(6)$ \\
\hline \multirow{10}{*}{ Ningaloo } & Acropora & 41 & 17 & 26 & $12(2)$ & $92(24)$ \\
\hline & Echinophyllia & 2 & 2 & 2 & $0(0)$ & $100(2)$ \\
\hline & Favia & 8 & 0 & 2 & - & $100(2)$ \\
\hline & Favites & 8 & 0 & 1 & - & $100(1)$ \\
\hline & Goniastrea & 7 & 1 & 1 & $0(0)$ & $100(1)$ \\
\hline & Hydnophora & 4 & 1 & 1 & $0(0)$ & $100(1)$ \\
\hline & Lobophyllia & 4 & 1 & 1 & $0(0)$ & $100(1)$ \\
\hline & Merulina & 2 & 2 & 2 & $0(0)$ & $100(2)$ \\
\hline & Montipora & 28 & 2 & 2 & $0(0)$ & $100(2)$ \\
\hline & Platygyra & 6 & 1 & 2 & $0(0)$ & $100(2)$ \\
\hline \multirow{10}{*}{ Abrolhos } & Acropora & 41 & 0 & 20 & - & $100(20)$ \\
\hline & Echinophyllia & 2 & 0 & 1 & - & $100(1)$ \\
\hline & Favia & 8 & 0 & 5 & - & $100(5)$ \\
\hline & Favites & 8 & 0 & 5 & - & $100(5)$ \\
\hline & Goniastrea & 7 & 0 & 2 & - & $0(0)$ \\
\hline & Hydnophora & 2 & 0 & 0 & - & - \\
\hline & Lobophyllia & 3 & 0 & 1 & - & $100(1)$ \\
\hline & Merulina & 1 & 0 & 1 & - & $100(1)$ \\
\hline & Montipora & 26 & 0 & 4 & - & $100(4)$ \\
\hline & Platygyra & 2 & 0 & 1 & - & $100(1)$ \\
\hline \multirow{10}{*}{ South West } & Acropora & 1 & 0 & 1 & - & $100(1)$ \\
\hline & Echinophyllia & 0 & 0 & 0 & - & - \\
\hline & Favia & 1 & 0 & 0 & - & - \\
\hline & Favites & 4 & 0 & 0 & - & - \\
\hline & Goniastrea & 2 & 0 & 2 & - & $50(1)$ \\
\hline & Hydnophora & 0 & 0 & 0 & - & - \\
\hline & Lobophyllia & 0 & 0 & 0 & - & - \\
\hline & Merulina & 0 & 0 & 0 & - & - \\
\hline & Montipora & 1 & 0 & 1 & - & $100(1)$ \\
\hline & Platygyra & 0 & 0 & 0 & - & - \\
\hline
\end{tabular}




\section{RESULTS}

222

\section{3}

224

225

226

227

228

229

230

231

232

233

234

235

236

237

238

239

240

241

242

243

244

245

246

247

248

249

250

\section{Regional patterns of coral reproduction: Kimberley Oceanic}

The oceanic reefs of the Kimberley are atolls rising from depths of several hundred meters, with over 300 species and 57 genera of hard corals. Coral cover in many habitats can be over 70\%, and much of the remaining substrata are covered in coralline and turf algae, with a very low cover of macroalgae and other benthic organisms. The Acroporidae are typically the dominant family of hard corals, followed by the Poritidae, Faviidae and Pocilloporidae, while soft corals are also common.

Coral reproduction has been investigated at all of the Kimberley oceanic reefs during one or more years (Supplementary Table 1). From Ashmore, Cartier, Scott and Seringapatam Reefs, and the Rowley Shoals, several thousand colonies from over 130 species and 30 genera have been sampled during the autumn and/or spring spawning seasons, in one or more years. Of the total number of Acropora species know in the region, approximately $62 \%$ were sampled in spring and $78 \%$ in autumn, compared to $20 \%$ and $32 \%$ of non-Acropora species, respectively (Table 1 ). The majority of the sampling has been conducted at Scott Reef, where there was sampling of colonies prior to the spawning in autumn and spring in consecutive years from 2007 to 2010, including repeated sampling of some tagged colonies. There has been comparatively little sampling at other times of year, so inferences about spawning during summer months may be underestimated. In most instances, the times of spawning were inferred from in situ ranking of gamete development, in addition to microscopic investigation of egg sizes and histological analyses of some spawning corals and brooding corals. Spawning has also been observed in situ on several occasions.

The existing data suggest that most species of corals on the oceanic atolls are broadcast spawners. Spawning has been inferred to occur primarily during spring and autumn, with a larger proportion of species and colonies participating in the autumn mass spawning than in the multispecific spawning during spring (Table 2; Supplementary Table 2). Many species participated in both spawning events, but most colonies spawn only once a year (i.e. within-population biannual spawning). Of the species of Acropora sampled in spring $(n=39)$ and autumn $(n=49), 90 \%$ were reproductively active in spring and $94 \%$ in autumn, compared to $10 \%$ in spring and $32 \%$ in 
251 autumn for the common non-Acropora species $(n=73)$ (Table 2; Supplementary Table 2). For the

252 species sampled repeatedly over several years, approximately $40 \%$ spawned only in autumn, less

253 than $10 \%$ only in spring, and approximately 55\% in both autumn and spring; within species, a

254 similar proportion ( $>30 \%$ ) of colonies spawning during each season. A similar pattern was

255 evident in the additional 30 species of Acropora and 20 species of non-Acropora sampled less

256 rigorously $\left(\mathrm{n}=5-10\right.$ colonies $\left.\mathrm{yr}^{-1}\right)$, but for a higher proportion of non-Acropora species and

257 colonies spawning in autumn; Favia stelligera and F. pallida spawned during both seasons and

258 Diploastrea heliopora spawned only during spring (Supplementary Table 2). More intensive

259 sampling of the non-Acropora species may increase the proportion of instances of within-species

260 biannual spawning among these species.

261 Within each season, spawning most commonly occurred during March and October, but varied

262 according to the timing of the full moon. Split-spawning occurred every few years during both

263 seasons and occasionally over consecutive years; splits usually occurring between March and

264 April in autumn, and October and November in spring, following full moons that fell in the last

265 week or so of the preceding months. Spawning has been observed directly in autumn and/or

266 spring during six years, and colonies were sampled before and after to check for the

267 disappearance of pigmented eggs. Based on these observations, spawning usually occurred 7-9

268 nights after the full moon during neap tides. However, the times of spawning varied among years

269 and occurred any time from the night of the full moon to around 10 days after.

270 The majority of corals showed evidence of spawning either in March and/or April, and October

271 and/or November, with the exception of the massive Porites. At the times of sampling during

272 autumn and spring, pigmented eggs were observed in only a few massive Porites colonies, but

273 massive Porites can spawn eggs with comparatively little pigmentation (Stoddart et al. 2012).

274 Histological analyses of samples collected at these times indicated that colonies were dioecious

275 and released eggs and sperm over several months in the year from spring to autumn. A peak in

276 reproductive activity was not obvious, and stages of gamete development indicated spawning

277 over several months from October to May, in contrast to the peak in spawning observed in

278 massive Porites on other reefs around Australia (Kojis \& Quinn 1982; Stoddart et al. 2012). The

279 sampling of all species was restricted a few months each year around two main spawning events,

280 and the extent of spawning following other lunar phases and months has not been investigated in 
281 detail. The potential exists for at least some colonies and/or species to spawn during other times.

282 For example, a small proportion of Acropora millepora, A. tenuis, A. polystoma, A. gemmifera 283 and Goniastrea edwardsii colonies at Ashmore Reef had pigmented eggs in early February or 284 September 2011, indicating they would either spawn a month earlier than most other corals or 285 would retain their eggs until the next month; alternately, early spawning in some corals during 2862011 could reflect higher than normal water temperatures. In addition the variation in times of 287 broadcast spawning, larval production in the brooding corals also occurs outside of the dominant 288 spawning events. Histological analyses confirmed that Isopora brueggemanni, I. palifera, 289 Seriatopora hystrix and Stylophora pistillata were brooding corals in the offshore Kimberley 290 region. Isopora brueggemanni and S. hystrix were most intensively sampled and contained 291 gametes in all stages of development and planula larvae during most months from October to 292 May. There was no clear peak in reproductive activity in the brooding corals and larvae were 293 apparently released over many months from spring to autumn.

294

295

296

297

298

299

300

301

302

303

304

305

306

307

308

309

\section{Regional patterns of coral reproduction: Kimberley}

There are diverse and extensive reef systems throughout Kimberley region, including inner shelf, fringing and patch reefs, exposed platforms and subtidal banks around the coastline and islands (Richards et al. 2014; Speed et al. 2013; Wilson 2013). There are over 300 species of hard corals from 71 genera, and clear cross-shelf differences in species distributions exist between the coastal and offshore locations, with 27 species (8\%) recorded only from nearshore locations and 111 species (33\%) recorded only at offshore locations (Richards et al. 2014). There are no quantitative data describing the relative abundances of corals throughout the inshore Kimberley, but qualitative descriptions highlight the considerable variation in habitats and coral assemblages. For example, leeward intertidal reefs may be characterised by branching and tabular Acropora; subtidal zones can have a high cover and diversity of corals dominated by massive Porites and species of Faviidae and foliose corals; exposed fringing reefs may have a comparatively low cover and diversity of corals dominated by massive Faviidae and soft corals; extensive tidal pools throughout the region can have a high cover and diversity of corals different to those in other zones (INPEX 2011; Wilson 2013). 
310 There are very few reproductive data for coral assemblages in the inshore Kimberley region, 311 particularly given the extent and diversity of the reefs (Supplementary Table 1). Inferences of 312 coral reproduction in the region are largely based on surveys during one or two years at a small 313 group of islands within the Bonaparte Archipelago (Figure 1). Several hundred colonies from 314 around 60 species and 15 genera were sampled during autumn or spring season, with sampling 315 focusing on species of Acropora (Table 1; Supplementary Table 2). Of the total number of 316 Acropora species know in the region, approximately $90 \%$ were sampled in spring and $40 \%$ in 317 autumn, compared to $30 \%$ and $4 \%$ of non-Acropora species, respectively. Inferences about 318 spawning during these seasons were drawn from in situ or microscopic examination of 319 pigmented eggs within colonies, and there are no observations of coral spawning for the inshore 320 Kimberley reefs.

321 The main season of spawning on inshore Kimberley reefs is probably during autumn, but with 322 second multi-specific spawning also occurring during spring at a similar time to the oceanic reefs 323 in the region (Table 2; Supplementary Table 2). Of the species of Acropora sampled in spring $324(n=35)$ and autumn ( $n=16), 42 \%$ were inferred to spawn in spring and $87 \%$ in autumn (Table 2).

325 Of the 60 common non-Acropora species, there was evidence of only 5\% spawning in spring and $3267 \%$ in autumn. The low proportion of non-Acropora spawning at these times suggests

327 reproductive activity outside the peak spring and autumn spawning windows by these taxa, $328 \mathrm{and} /$ or is a consequence of low replication and a possible split-spawning. Although not observed 329 in situ, spawning by a few species of Mussidae and Faviidae in aquaria at Kimberley Marine 330 Research Station (KMRS) at Cygnet Bay occurred at a similar time as at the oceanic reefs during 331 two years, 7-9 nights after full moon in March (A. McCarthy \& A. Heyward, pers. comm.). 332 There is currently no evidence of spawning in the inshore reefs of the Kimberley occurring a 333 month earlier than on the oceanic reefs, as tends to occur on parts of the Great Barrier Reef. If 334 this was to occur in the Kimberley, spawning on the inshore reefs would be expected in February 335 or March in autumn, and September or October in spring. Although sampling has not been 336 conducted during these months, the existing data demonstrate that spawning did not occur 337 exclusively a month earlier than on the oceanic reefs and that multi-specific spawning events 338 have also occurred later in the season, during April in autumn and November in spring. Evidence 339 for late spawning during autumn and spring may reflect a split-spawning during the years of 340 sampling, as on the oceanic reefs. 
341 Of 31 species sampled from seven genera on the inshore Kimberley reefs during late March, 30

342 had pigmented eggs and were likely to spawn in early April. This included many species that 343 were sampled with low ( $\leq 5$ colonies) replication, indicating that autumn is the main season of 344 spawning. Indeed, based on the timing of the full moon and spawning on the oceanic reefs, the 345 autumn spawning during that that year (2007) was likely spilt; so many colonies and species may 346 have also spawned in early March, providing further evidence for autumn being the primary 347 season of spawning for the region. Of 63 species sampled in late October, 25\% contained 348 pigmented eggs and were likely to spawn in early November, of which the majority were 349 Acropora; $37 \%$ of the 35 species of Acropora contained pigmented eggs. However, eggs were 350 absent from many of the colonies sampled with low replication ( $\leq 5$ colonies) and the spring 351 spawning may have been split, based on the timing of the full moon and the data for the oceanic reefs. Consequently, a proportion of colonies and species probably spawned in early October and future work may identify a higher proportion of species and colonies participating in a spring spawning. It remains to be determined whether the inshore reefs of the Kimberley display a similar degree of spawning synchrony during any one month in autumn and spring as on the oceanic reefs, or whether inshore spawning is more protracted over several months with seasonal peaks around autumn and spring, as may be the case on Indonesian reefs to the north (Baird et al. 2009). There are few data for the non-Acropora corals, which are most likely to have less synchronous patterns of spawning, and nor are there currently any data for brooding corals that are probably common throughout parts of the region. The brooding corals in the Kimberley are likely to display similar patterns of reproduction to those at the oceanic reefs, with planulation occurring during many months through spring to autumn, and perhaps extending into some winter months.

\section{Regional patterns of coral reproduction: Pilbara} There are extensive near-shore and mid-shore reefs systems throughout the Pilbara. Within the region much of the available information exists for the Damiper Archipelago (e.g. Blakeway \& Radford 2004; Griffith 2004; Marsh 2000; Richards \& Rosser 2012; Veron \& Marsh 1988) and there is less information for reefs in the west Pilbara (but see Marsh 2000; Richards \& Rosser 2012; Veron \& Marsh 1988). The general pattern of coral diversity is similar throughout the 
371 Pilbara, with between 200 and 230 species recorded at the Dampier Archipelago, and at the mid-

372 shore Montebello and Barrow Island reefs. A slightly higher number recorded at the Dampier

373 Archipelago may be due to greater diversity of habitats and environmental conditions (Griffith

374 2004; Marsh 2000; Richards \& Rosser 2012). However, there are distinct assemblages of coral

375 species among the inshore reefs and those throughout the archipelago, reflecting the cross-shelf

376 variation in environmental conditions and habitat types (Blakeway \& Radford 2004; Richards \&

377 Rosser 2012). Average total hard coral cover for the inshore reefs of the Pilbara is approximately

$37820 \%$, with the dominant families Faviidae and Dendrophylliidae having contributed to much of

379 this cover (Speed et al. 2013). However, coral community composition can also vary

380 dramatically among the inshore reefs and species of Acropora, Faviidae, Platygyra, Turbinaria

381 and Pavona are common in some communities (Blakeway \& Radford 2004). The outer reefs of

382 the west Pilbara can have communities characteristic of clearer water, with approximately twice

383 the coral cover and a higher diversity. In particular, within the back-reef habitats many massive

384 Porites colonies are associated with extensive coral assemblages, including a high cover $(>50 \%)$

385 of Acropora (Marsh 2000; Speed et al. 2013).

386 Coral reproduction in the Pilbara region has been investigated at several reefs, with over 1000

387 colonies sampled from 115 species, during one or more years (Supplementary Table 1). Of the

388 total number of Acropora species know in the region, $71 \%$ and $88 \%$ were sampled in spring and

389 autumn, respectively, compared to $28 \%$ and $46 \%$ for the non-Acropora species (Table 1;

390 Supplementary Table 2). By far the majority of these data were from the Dampier Archipelago,

391 and the times of reproduction were inferred from in situ ranking of gamete development,

392 microscopic investigation of egg sizes and histological analyses of some spawning and brooding

393 corals. Spawning has also been observed in situ on several occasions. Given the frequency and

394 timing of disturbances to Pilbara reefs in recent years, including dredging operations,

395 temperature anomalies and cyclones, some data from the region were probably biased by coral

396 colonies having insufficient energy reserves to invest in reproduction. In these instances, the

397 proportion of species and colonies reproducing could be underestimated.

398 The first discovery of coral spawning in Western Australia was in the Dampier Archipelago

399 (Simpson 1985). Early research showed corals spawning exclusively in autumn over two

400 consecutive years, in 46 species of coral from seven families. The presence of mature eggs in

401 some non-Acropora species after the main spawning event indicated split-spawning over two 
402 consecutive lunar cycles, but there was no evidence of spawning during spring. Subsequent 403 research has documented multi-specific spawning by a small proportion of colonies and species 404 during spring (October to December). Within the Dampier Archipelago, a small number of 405 tagged colonies seemed to spawn consistently either in autumn or in spring and have only one 406 gametogentic cycle. Of the species of Acropora sampled in spring $(n=35)$ and autumn $(n=43)$, $40734 \%$ were inferred to spawn in spring and 98\% in autumn (Table 2; Supplementary Table 2). Of 408 the 69 common non-Acropora species, 43\% spawned in autumn and one spawned in spring, 409 although few were sampled in spring. Among the non-Acropora species, only Favites flexuosa, 410 and possibly Favites pentagona and Montipora undata are thought to spawn in spring or early 411 summer, while the proportion of colonies within species of Acropora known to spawn during 412 spring is generally low $(<20 \%$ ) (Table 2; Supplementary Table 2). Sampling around a split413 spawning and with environmental stress has potentially underestimated the participation by 414 corals in the spring spawning (October to December), but the primary spawning period is 415 certainly autumn (usually March).

416 Many Pilbara reefs are dominated by corals such as massive Porites, Pavona decussata and 417 Turbinaria mesenterina, which display different patterns of reproduction to most hermaphroditic 418 species that participate exclusively in the spring and/or autumn spawning events. Within the 419 Dampier Archipelago, repeated histological examination showed that these three taxa were gonochoric. Spawning occurred predominantly in December in the massive Porites (mainly $P$. lobata), as on the Great Barrier Reef (Harriott 1983). For Pavona decussata, spawning occurred

422 during March and April, possibly due to split-spawning during that year (2007). In Turbinaria mesenterina, spawning occurred over several months, possibly from November to April. While T. mesenterina retained eggs after this period, this does not indicate imminent spawning as this

425 species has been reported to have a gametogenic cycle of more than 12 months (Willis 1987).

426 While spawning has not been observed, frequent sampling of $P$. lutea demonstrated that it 427 spawned during spring tides predominantly 3 days (2-4 days) after the full moon, in contrast to 428 the usual times of spawning during neap tides approximately one week after the full moon. In 429 addition to these spawning corals, the main periods of reproductive output for the brooding 430 corals in the Pilbara are also likely to occur at times other than during the dominant spawning 431 periods in autumn and spring. Although cycles of gametogenesis in brooding corals have not yet 
432 been investigated in the Pilbara, they probably culminate in the release of planula larvae over

433 several months through spring to autumn, and possibly into winter months.

434

435

436

437

438

439

440

441

442

443

444

445

446

447

448

449

450

451

452

453

454

455

456

457

458

459

460

\section{Regional patterns of coral reproduction: Ningaloo}

Ningaloo is an extensive fringing reef system almost $300 \mathrm{~km}$ in length, with diverse coral communities and over 200 species of hard corals from 54 genera (Veron \& Marsh 1988). Mean coral cover can be as high as $70 \%$ at areas of the reef flat and reef slope, but is typically less at other habitats such as in the lagoon (Speed et al. 2013). The remaining benthic cover is composed of coralline and turf algae, seasonal macroalgae growth and other benthic organisms. Within the coral communities, the Acroporidae are often most abundant, but the Faviidae, Poritidae, Pocilloporidae and soft corals are also common (Speed et al. 2013; Veron \& Marsh 1988). The deeper lagoons typically contain massive Porites bommies and patches of staghorn Acropora, while the outer-slope is dominated by robust corals with massive and encrusting growth forms, often Platygyra sinensis and prostrate Acropora (Wilson 2013).

There is detailed reproductive data for some species at one location at Ningaloo and a comparatively poor understanding of spatial variation across this extensive system (Supplementary Table 1). Coral reproduction has been investigated during several years, for several hundred colonies from 42 species and 11 genera (Table 1). Of the total number of Acropora species know in the region, approximately $44 \%$ were sampled in spring and $67 \%$ in autumn, compared to $14 \%$ and $20 \%$ of non-Acropora species, respectively. Most data exist for several species of Acroporidae and Faviidae sampled during one or more months from spring to autumn at Coral Bay. Early work at Ningaloo suggests some variation in the time of spawning may exist among locations, with a higher proportion of corals spawning in March in the north and in April to the south, but this may also have been a consequence of split-spawning. Nonetheless, the studies of coral spawning at Coral Bay provide detailed information about temporal variation in spawning among months, lunar cycles, and the nights of spawning in autumn. Inferences about spawning times were drawn from in situ ranks of gamete development and microscopic investigation of egg sizes in random population samples and by re-sampling individual colonies, in addition to direct observations of spawning in situ. 
461 Mass spawning at Ningaloo occurs during autumn, with a more protracted period of spawning

462 over consecutive months, and little or no multi-specific spawning during spring (Table 2;

463 Supplementary Table 2). Of the species of Acropora sampled in spring $(n=17)$ and autumn

$464(n=26), 12 \%$ were inferred to spawn in spring and $92 \%$ in autumn, with one spawning

465 exclusively in summer. Of the 69 common non-Acropora species, none were reproductively

466 active in spring, compared to $20 \%$ in autumn (Table 2; Supplementary Table 2). However, a low

467 proportion of species $(<20 \%)$ and particularly colonies have been sampled during spring.

468 Additionally, there are very few reproductive data from parts of Ningaloo other than Coral Bay.

469 Most Acroporidae and Faviidae colonies at Coral Bay participated in mass spawning during a

470 single month in autumn, but a small proportion of many species also spawned during other

471 months through summer and autumn. Species typically spawned during one or two consecutive

472 months, with no evidence of spawning during discrete months or of a multi-specific spawning

473 during spring, as on northern reefs. There are numerous observations of slicks of coral spawn

474 during spring, but the extent to which these are a product of multi-specific spawning remains

475 unknown (R Babcock \& D Thompson pers. comm.). Within species, individual colonies had a

476 single gametogenic cycle and usually spawned within a few consecutive nights. The mass

477 spawning usually occurred during neap tides in late March or early April, 7-10 nights after the

478 preceding full moon, but a small proportion of colonies of several species also spawned

479 following the full moon or the new moon during months either side of the mass spawning.

480 Within the species spawning during autumn, most of their colonies $(60-100 \%)$ participated in

481 the mass spawning in early April following the full moon in late March, but during other years

482 mass spawning occurred in the last week of March following an earlier full moon in March.

483 Around the quantified mass spawning events in early April, a relatively small $(<20 \%)$

484 proportion of colonies from most species also spawned a month earlier (early March) or later

485 (early May), following the preceding full moon or new moon, particularly in the non-Acropora

486 species. A higher proportion (10-20\%) of these colonies spawned during March than in May $(<$

$48710 \%$ ), which may be due to a split-spawning during the years of sampling or may be typical of a

488 more protracted spawning at Ningaloo. Early observations suggest that split-spawning is a

489 common feature at Ningaloo, but whether it occurs during the same years and involves a similar

490 proportion of species and colonies as on reefs further north remains to be determined. Cooler

491 waters at Ningaloo could result in slower rates of gametogenesis and an increased likelihood of 
492 split-spawning during years in which a full moon falls early in March, and/or a higher proportion

493 of colonies participating in an April spawning than on northern reefs.

494 There was little evidence of spawning at Ningaloo during months other than in autumn. Less

495 than a few percent of colonies of Goniastrea retiformis, A. humilis and A. papillarae had visible

496 eggs in October, but none were pigmented and the times of spawning were unknown. Existing

497 data suggests that $A$. papillarae is the only species that does not participate in mass spawning

498 and spawns exclusively during summer, probably during December and/or January.

499 Additionally, a small proportion ( $<5 \%$ ) of Echinopora lamellosa also spawned during summer in

500 February, but with a higher proportion spawning during March $(\approx 13 \%)$ and particularly April $(\approx$

$50180 \%$ ). There are currently no data for species of corals such as massive Porites known to spawn

502 during summer at other reefs throughout WA. Given that spawning seems to be more protracted

503 at Ningaloo, future work may identify a higher proportion of species and colonies spawning

504 during summer, particularly for the non-Acropora. There is also no existing information for the

505 times of planulation in brooding corals at Ningaloo, but planula release is likely to occur at

506 similar times to other northern reefs, from spring through to autumn, with perhaps a lower

507 incidence in spring due to the cooler water temperatures.

508

509

510 Regional patterns of coral reproduction: Abrolhos Islands and Shark Bay

511 The Houtman Abrolhos Islands have the highest latitude coral reefs in Western Australia. The

512 coral communities are scattered among four islands, situated $<100 \mathrm{~km}$ from the coastline but

513 near the edge of the continental shelf, with over 180 species from 42 genera of corals (Veron \&

514 Marsh 1988). Coral cover ranges between 35 and 85\% among habitats (Dinsdale \& Smith 2004),

515 with an average cover for the region of approximately 44\% (Speed et al. 2013). Unlike studies on

516 a comparable latitude on the east coast of Australia (Harriott \& Banks 2002), the Abrolhos

517 maintains high percentages of tabulate and particularly staghorn Acropora (Abdo et al. 2012;

518 Dinsdale \& Smith 2004). Much of the remaining substrata were covered in turf and coralline

519 algae, although patches of macroalgae are also common. Situated to the north of the Abrolhos

520 Islands, Shark Bay is a large shallow bay $\left(\sim 12,950 \mathrm{~km}^{2}\right)$ with an average depth of $9 \mathrm{~m}$ and is 
521 enclosed by a number of islands (Veron \& Marsh 1988). The bay consists of vast seagrass

522 meadows (Wells et al. 1985) and coral growth is restricted to waters with oceanic salinity, such

523 as in the western side of the bay (Veron \& Marsh 1988), where 82 species from 28 genera of

524 hard corals have been recorded (Veron \& Marsh 1988). Corals from the families Acroporidae

525 and Dendrophylliidae are found in similar abundance of approximately $10-15 \%$ cover, and other

526 genera found in low $(<2 \%)$ cover include Montipora, Platygyra, Pocillopora, and Porites

527 (Bancroft 2009; Cary 1997; Moore et al. 2011; Speed et al. 2013).

528 Coral reproduction has primarily been investigated during one year at the Abrolhos Islands, 529 around the predicted time of mass spawning in autumn (Supplementary Table 1). Of the total 530 number of species know in the region, approximately 49\% of the Acropora and 34\% of the non531 Acropora were sampled in autumn, but with no sampling at other times of the year (Table 1).

532 Several hundred colonies from 107 species and 10 families were sampled in March 1987, and a 533 small random sample of colonies during late February 2004 (Supplementary Table 2). Most 534 samples were from species of Acropora and Faviidae around the Wallabi group of islands. The 535 times of spawning were inferred from in situ ranking of gamete development, microscopic 536 investigation of egg sizes and stages, and direct observation of spawning in situ and in aquaria.

537 In addition to random sampling, tagged colonies were re-sampled before and after the main 538 nights of spawning.

539 There is clearly a mass spawning by a high proportion of many Acropora species at the Abrolhos 540 Islands during autumn, but no knowledge of whether corals also spawn during spring or summer 541 (Table 2, Supplementary Table 2). Of the 107 species sampled, 58 species participated in the 542 main two nights of spawning in March, with a further 36 species likely to spawn on other nights 543 during March; a similar proportion of Acropora (49\%) and non-Acropora (31\%) participated in 544 the March spawning. Spawning occurred primarily over the 10 and 11 nights after the full moon, 545 during spring tides of small amplitude $(<2 \mathrm{~m})$, with reports of other spawning events also 546 between 8 and 11 nights after the full moon. In addition to the species and colonies that spawned 547 over a few consecutive nights, there was also evidence of a more protracted spawning by many 548 colonies and species over a greater number of nights, and possibly also during April and/or other 549 seasons. Within the species of mass-spawners, the mean number of colonies participating was $55070 \%$, and ranged between 10 and 100\%. Most species spawned over a few nights, but within the 551 assemblage spawning was probably protracted over almost three weeks, as early as a few nights 
552 before the full moon and up to two weeks later. Additionally, gametes were absent from a

553 variable proportion of colonies in approximately half the species observed to spawn in March, 554 and from all colonies in an additional 13 species, suggesting they either did not spawn during

555 that year or were likely to spawn during a different season. Slicks of spawn have also been

556 observed at the Abrolhos in February, although subsequent sampling suggested the bulk of the

557 community was likely to spawn in March. The species known to spawn during months other than

558 March on more northern reefs were either not sampled, or had a proportion of colonies without

559 eggs and were sampled in low replication. There is currently no reproductive information for

560 brooding corals, which are likely to release planulae over several months from spring to autumn,

561 but with perhaps a reduced reproductive window due to cooler water temperatures.

562

\section{Regional patterns of coral reproduction: Southwest Region}

564 Within the temperate southwest region of WA, corals are near their geographical limit. Reefs

565 where corals are known to occur include Rottnest Island, Hall Bank, and some patches of reef

566 within lagoons adjacent to the Perth mainland, such as at Marmion and Jurien. Rottnest Island

567 has the most abundant coral communities, with 25 species from 16 genera. Pocillopora

568 damicornis dominates certain areas (Veron \& Marsh 1988), which is a consequence of clonal 569 reproduction (Stoddart 1984). Clonal reproduction may also be important for other species at

570 Rottnest Island with more tropical affinities, such as Acropora sp. and Porites lutea (Crane

571 1999). Among the remaining corals, the dominant taxa are species of Favidiiae with subtropical

572 affinities, such as Goniastrea australiensis. Macroalgae (Sargassum and Ecklonia) are common

573 around Rottnest Island and contribute up to $60 \%$ of benthic cover (Wells \& Walker 1993).

574 Between Rottnest Island and the Perth metropolitan coastline is Hall Bank, a small reef with a

575 low diversity (14 spp.) but a high cover ( $\approx 50 \%)$ of corals, of which most are Favites and

576 Goniastrea (Thomson \& Frisch 2010). In contrast, the reefs adjacent to the coastline have a

577 lower coral diversity and cover, such as Marmion lagoon with 10 species from eight genera

578 (Veron \& Marsh 1988). Fleshy macroalgae are dominant on most of the temperate reefs, but

579 corals are can often be found among the algae in low density (Thomson et al. 2012). The most

580 abundant coral on these reefs is Plesiastrea versipora, one of the Indo Pacific's most widespread 
581 corals, however it rarely reaches large sizes and other species tend to have higher cover (e.g.

582 Goniastrea spp. Montipora capricornis).

583 Throughout the southwest region, coral reproduction has been investigated only at Rottnest

584 Island during one or more years throughout the 1980s and (Supplementary Table 1). At Rottnest

585 Island, a total of nine species and $>600$ colonies were sampled over multiple seasons, for months

586 to years (Table 1). The majority of the sampling has been conducted at two sites, which includes

587 consecutive sampling and spawning observations of colonies prior to spawning around summer

588 and autumn from January to May. Histological analyses were also used to investigate

589 reproduction in three species (Pocillopora damicornis, Alveopora fenestrata and Porites lutea)

590 from December to April. Mature gametes were found in colonies of the most abundant spawning

591 corals over several months through summer and autumn (Table 2, Supplementary Table 2).

592 Histological analyses revealed Pocillopora damicornis at Rottnest Island to be both a brooding

593 and spawning coral. Gametes and planula larvae were common in colonies through summer to

594 winter (December to early April), being most common in March, and rare or absent in winter.

595 The available data for the southwest region are only from Rottnest Island where spawning by the

596 dominant species appears to occur through summer and or autumn months (e.g. Goniastrea

597 aspera, G. australensis, Montipora mollis and Symphillia wilsoni), a pattern similar to that seen

598 on the subtropical reefs of Australia's east coast. Some colonies have been observed to spawn

599 around the time of new moon rather than full moon, such as Symphyllia wilsoni, and Alveopora

600 fenestsrata. Among the other dominant coral species in the region, there appears to be an

601 extended reproductive season of two or more months at different times of year for different

602 corals; for example, in summer for Pocilloproa damicornis, in early autumn for Turbinaria

603 mesenterina. The apparent staggering of reproduction among species between February and May

604 suggests that there is a relatively low level of synchrony within the temperate coral communities,

605 but with perhaps a higher degree of synchrony among some conspecific colonies in late summer

606 (Supplementary Table 2). Because the species composition and level of coral cover varies so

607 markedly among coral assemblages in the southwest, there is little or no knowledge of spatial

608 variation in community reproduction throughout the region. For example, Plesiastrea versipora

609 is numerically the most common coral in the region and across southern Australia, yet its

610 reproductive biology in temperate waters is still poorly understood. It is recorded as a mass

611 spawner on tropical reefs (Magnetic Island, Babcock et al. 1986; Taiwan, Dai et al. 1992), but 
612 did not spawn with other subtropical corals such as G. australiensis in Moreton Bay, on the east

613 coast of Australia (Fellagara et al. (2013). There is no knowledge of the distribution and patterns

614 of reproduction in brooding corals through the southwest region, with the exception of

615 Pocillopora damicornis at Rottnest Island.

616

617

618

619

620

621

622

623

624

625

626

627

628

629

630

631

632

633

634

635

636

637

638

639

640

\section{DISCUSSION}

\section{Summary of coral reproduction across Western Australia}

The observed differences in reproduction among Western Australian (WA) coral reefs are due to their varying community composition, modes of reproduction, and the cycles of gametogenesis for coral species. The most obvious differences in community composition are the higher abundance and diversity of Acroporidae and massive Porites on offshore reefs and tropical reefs north of the Abrolhos Islands. Among the inshore reefs and those south of the Abrolhos Islands, species of Faviidae, Pocilloporidae, Turbinaria and/or Pavona are more common and there is a notable decline in the abundance and diversity of coral species (Lough \& Barnes 2000; Speed et al. 2013; Veron \& Marsh 1988). Beyond the effect of community composition, the modes of reproduction displayed by the different coral species distinguished their cycles of gametogenesis and times of reproductive output.

As on most tropical reefs around the world, the dominant mode of coral reproduction on WA coral reefs is broadcast spawning. Within a year, most individual corals have a single cycle of gametogenesis that culminates in spawning during one or a few consecutive nights each year. However, the times of spawning and the degree of synchrony among and within species vary among the different regions, with a latitudinal gradient in the spawning activity among seasons. The primary period of spawning on all WA reefs (apart from the southwest region) is in autumn, often culminating in the mass spawning of a relatively high proportion of species and colonies during March and/or April.

Successive studies have added to the list of species known to mass spawn during autumn, but also to the list known to participate in a second multi-specific spawning during spring (October 
641 and/or November) on many WA reefs. The existing data suggest that biannual spawning by

642 communities during autumn and spring is a phenomenon that occurs with increasing frequency

643 from Ningaloo Reef north. Although more intensive sampling is necessary to clearly establish a

644 latitudinal gradient, synchronous spawning by multiple species and colonies in the spring

645 spawning is highest on the Kimberley Oceanic reefs, decreases considerably on Pilbara reefs,

646 and may not occur on Ningaloo Reefs - there is only anecdotal evidence of multi-specific

647 spawning at Ningaloo Reef in spring. Of the 17 species of biannual spawners on the Kimberley

648 Oceanic reefs that were sampled most rigorously in the other regions of WA, all spawned in

649 autumn and five during spring in the Pilbara, and all spawned in autumn and none during spring

650 at Ningaloo (Table 2). In addition to the reduction in spring spawning with increasing latitude,

651 spawning may also become more protracted over consecutive nights or weeks around the mass

652 spawning in autumn from reefs in the Kimberley to the Abrolhos Islands (Table 2), although

653 more data are again required to confirm this pattern.

654 Within these seasons, there is a comparatively poor understanding of spatial and temporal

655 variation in spawning times (months, weeks, time of day). Mass spawning occurs most

656 commonly in March and/or April, and the multi-specific spawning in October and/or November,

657 often varying according to the timing of the full moon. As with coral communities on the Great

658 Barrier Reef, spawning on WA reefs can be split over consecutive months in autumn and spring,

659 depending on the timing of the full moon. The phenomenon typically occurs every few years, but

660 can also occur in consecutive years. The nights of spawning were typically inferred from the

661 presence of pigmented eggs in colonies days to weeks before the predicted dates, with very few

662 direct observations of spawning and limited sampling conducted after the event. There is

663 certainly a peak in spawning activity (mass spawning) over a few nights each year on most reefs,

664 but with a variable participation by colonies and species in this primary spawning event. Most

665 commonly, mass spawning occurs during neap tides between approximately 7 to 12 nights after

666 the full moon, usually in March and/or April, on all reefs but for those in the temperate

667 southwest region. However, intensive sampling of colonies over days and weeks at Ningaloo

668 Reef has also documented spawning around the time of the new moon, as can occur in some

669 species on the GBR (Babcock et al. 1986). Whether this pattern reflects a more protracted

670 spawning that is unique to Ningaloo Reef, or is a feature of other WA reefs remains to be

671 determined. 
Table 2. Regional variation in spawning for coral species sampled most rigorously on Western Australian reefs. Regions are colour coded according to Figure 1. Seasons and months are: Spring (Spr), September (s), October (o), November (n); Summer (Sum), December (d), January (j), February (f); Autumn (Aut), March (m), April (a), May (m). Spawning has not been recorded during Winter months (June, July, August) in Western Australia and they have been excluded. Taxonomic revisions are summarised in Supplementary Table 2. Based on the available data, the sampling design and the methods used, confidence in the inferred months of spawning were ranked qualitatively according to:

Confident. Evidence based on the presence of pigmented eggs in colonies prior to the predicted dates of spawning in many colonies, sites and years; the presence and absence of pigmented eggs in many colonies around the predicted dates of spawning; and/or direct observations of spawning in multiple colonies.

Likely. Evidence based on the presence of pigmented eggs in many colonies prior to the predicted dates but with limited spatial and temporal replication; and/or most evidence indicates spawning during this month but with some contradictory data among studies.

Possible. Evidence based on the presence of large but unpigmented eggs several weeks prior to the predicted dates of spawning; and/or contradictory data among studies due to sampling design, methodology or species identification.

Unlikely. No evidence of spawning; pigmented or large unpigmented eggs absent from samples of many colonies, sites and years within several weeks of the predicted dates of spawning.

\begin{tabular}{|c|c|c|c|c|c|c|c|c|c|c|c|c|c|c|c|c|c|c|c|c|c|}
\hline \multirow[t]{2}{*}{ Species } & \multicolumn{3}{|c|}{ Kimberley Oceanic } & \multicolumn{3}{|c|}{ Kimberley } & \multicolumn{3}{|c|}{ Pilbara } & \multicolumn{4}{|c|}{ Ningaloo } & \multicolumn{4}{|c|}{ Abrolhos } & \multicolumn{4}{|c|}{ South West } \\
\hline & $\mathrm{Spr}$ & Sum & Aut & $\mathrm{Spr}$ & Sum & Aut & $\mathrm{Spr}$ & Sum & Aut & $\mathrm{Spr}$ & Sum & & Aut & $\mathrm{Spr}$ & Sum & $\mathrm{Au}$ & ut & $\mathrm{Spr}$ & Sun & & Aut \\
\hline & \begin{tabular}{|l|l|l|}
$\mathrm{s}$ & 0 & $\mathrm{n}$ \\
\end{tabular} & \begin{tabular}{l|l|l}
$d$ & $j$ & $f$ \\
\end{tabular} & 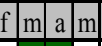 & \begin{tabular}{l|l|l|}
$\mathrm{s}$ & $\mathrm{o}$ & $\mathrm{n}$ \\
\end{tabular} & $\mathrm{d} \mid \mathrm{j}$ & \begin{tabular}{l|l|l|l|}
$\mathrm{f}$ & $\mathrm{m}$ & $\mathrm{a}$ & $\mathrm{n}$ \\
\end{tabular} & \begin{tabular}{|l|l|l|}
$\mathrm{s}$ & $\mathrm{o}$ & $\mathrm{n}$ \\
\end{tabular} & \begin{tabular}{|l|l|}
$d$ & $j$ \\
\end{tabular} & \begin{tabular}{l|l|l|l|}
$\mathrm{f}$ & $\mathrm{m}$ & $\mathrm{a}$ & $\mathrm{m}$ \\
\end{tabular} & \begin{tabular}{|l|l|l}
$\mathrm{s}$ & $\mathrm{o}$ & $\mathrm{n}$ \\
\end{tabular} & \begin{tabular}{|l|l|l}
$n$ & $d$ & $j$ \\
\end{tabular} & \begin{tabular}{l|l|}
$\mathrm{f}$ & $\mathrm{m}$ \\
\end{tabular} & $\mathrm{a} \mid \mathrm{m}$ & \begin{tabular}{|l|l|l|}
$\mathrm{s}$ & $\mathrm{o}$ & $\mathrm{n}$ \\
\end{tabular} & $\begin{array}{lll}n & d & j \\
\end{array}$ & \begin{tabular}{|l|l|l|}
$\mathrm{f}$ & $\mathrm{m}$ & $\mathrm{a}$ \\
\end{tabular} & $\mathrm{m}$ & \begin{tabular}{l|l|l}
$\mathrm{s}$ & $\mathrm{o}$ & $\mathrm{n}$ \\
\end{tabular} & \begin{tabular}{l|l|l}
$n$ & $d$ & $j$ \\
\end{tabular} & \begin{tabular}{l|l}
$\mathrm{f}$ & $\mathrm{m}$ \\
\end{tabular} & $\mathrm{a} \mathrm{m}$ \\
\hline Acropora aspera & & & & & & & & & & & & & & & & & & & & & \\
\hline Acropora cytherea & & & & & & & & & & & & & & & & & & & & & \\
\hline Acropora digitifera & & & & & & & & & & & & & & & & & & & & & \\
\hline Acropora florida & & & & & & & & & & & & & & & & & & & & & \\
\hline Acropora gemmifera & & & & & & & & & & & & & & & & & & & & & \\
\hline Acropora humilis & & & & & & & & & & & & & & & & & & & & & \\
\hline Acropora hyacinthus & & & & & & & & & & & & & & & & & & & & & \\
\hline Acropora intermedia & & & & & & & & & & & & & & & & & & & & & \\
\hline Acropora latistella & & & & & & & & & & & & & & & & & & & & & \\
\hline Acropora microphtha & & & & & & & & & & & & & & & & & & & & & \\
\hline Acropora millepora & & & & & & & & & & & & & & & & & & & & & \\
\hline Acropora samoensis & & & & & & & & & & & & & & & & & & & & & \\
\hline Acropora secale & & & & & & & & & & & & & & & & & & & & & \\
\hline Acropora spicifera & & & & & & & & & & & & & & & & & & & & & \\
\hline Acropora tenuis & & & & & & & & & & & & & & & & & & & & & \\
\hline Favia pallida & & & & & & & & & & & & & & & & & & & & & \\
\hline Favia stelligera & & & & & & & & & & & & & & & & & & & & & \\
\hline Favites halicora & & & & & & & & & & & & & & & & & & & & & \\
\hline Goniastrea aspera & & & & & & & & & & & & & & & & & & & & & \\
\hline Goniastrea australen & & & & & & & & & & & & & & & & & & & & & \\
\hline Goniastrea retiformis & & & & & & & & & & & & & & & & & & & & & \\
\hline Lobophyllia hemprich & & & & & & & & & & & & & & & & & & & & & \\
\hline Merulina ampliata & & & & & & & & & & & & & & & & & & & & & \\
\hline Platygyra daedalea & & & & & & & & & & & & & & & & & & & & & \\
\hline
\end{tabular}


674 Despite some brooding corals being widely distributed and abundant on many of WA's coral 675 reefs (e.g. species of Pocilloporidae and Isopora), there is currently little information about their 676 cycles of gametogenesis and times of planulae release. Within a year, brooding corals on WA 677 reefs probably have multiple cycles of gametogenesis culminating in the release of planluae 678 larvae over several months, similar to those on the GBR (Harriott 1983b; Harrison et al. 1990; 679 Kojis 1986; Tanner 1996; Wallace et al. 2007). On the Kimberley Oceanic reefs, planulae were 680 present within Isopora brueggemanni and Seriatopora hystrix during several months through 681 spring to autumn. Brooding corals on other WA reefs probably have similar cycles of 682 planulation, but for perhaps a shorter reproductive window on higher latitude reefs. The relative 683 proportion of planulae produced during different months of the year and the nights of their 684 release relative to the phases of the moon are unknown for all brooding corals on all reefs.

\section{Methods for assessing coral reproduction}

687 Consideration of coral reproduction is often required by environment mangers where 688 development activities are proposed on or near coral reefs. The principle being that if coral 689 spawning and larval settlement are concentrated during a discrete period then the potential impacts from development works can be minimised. Rigorous sampling and interpretation of reproductive status in coral communities is needed well in advance to provide time for planning; sampling is also needed to continue throughout to confirm predictions about time(s) of spawning. In all cases, the accurate prediction of the timing, magnitude and duration of coral spawning is vital given the logistical complexity of development operations and the cost of delays. Many early studies of coral reproduction employed rigorous, and often complimentary, methods because so few data existed. The resulting publications provided a detailed description of the methodology and the assumptions on which conclusions were based. Attempts to quantify cycles of reproduction today require a good knowledge of this background literature, and particularly the limitations of the different approaches. The most relevant literature and methods for a particular study will depend on the questions to be addressed, the regions in which the reefs are found and the species to be investigated. However, to maximise the knowledge gained and minimise the biases from sampling effort, many publications should first be read and understood; 
704 1983; Fan \& Dai 1995; Fong \& Glynn 1998; Glynn et al. 1994; Glynn et al. 1991; Harrison

705 1993; Harrison et al. 1990; Heyward \& Collins 1985; Sakai 1997; Sebens 1983; Shlesinger et al.

706 1998; Stoddart 1983; Stoddart \& Black 1985; Szmant-Froelich et al. 1985; Szmant \& Gassman

707 1990; Wallace 1985). In the context of environmental management, we provide some comments

708 on the experimental design and methodology used in coral reproductive studies in Western

709 Australia, which also provides some background to a thorough reading of the existing literature.

710

711 Community composition: For environmental management, information about coral

712 reproduction is often required at the level of the entire community. Thus, there is a need to assess

713 the composition of coral communities across the susceptible reefs, habitats and sites, in order to

714 quantify the relative dominance of the species. As the species list of corals at tropical reefs can

715 be extensive, a convenient cut-off point must be chosen. Therefore, we suggest that the species

716 be ranked in terms of their contribution to total coral cover, and those making a cumulative

717 contribution to most $(\approx 80 \%)$ cover across all communities of interest be chosen for assessment of

718 reproductive behaviour. However, consideration must also be given to whether certain species,

719 although low in relative abundance, play a critical role in ecosystem maintenance (e.g. keystone

720 species).

721

722 Taxonomic resolution: Coral taxonomy and the identification of species for sampling are

723 problematic in virtually any study of tropical coral communities; the issue cannot be understated.

724 Identification to the finest taxonomic resolution possible is always desirable, however the

725 suggested approach of quantifying seasonal reproductive patterns for dominant taxa would work

726 equally well for higher taxonomic groups. For example, a more practical approach depending on

727 the diversity of species and the taxonomic skills of the researchers would be to group species

728 according to a higher taxonomic level (e.g. Genus, Family) and to also consider growth form

729 (e.g. massive, branching, encrusting, corymbose) and reproductive mode (spawner, brooder).

730 The advantage with this approach is that uncertainty around the identity of species is obvious,

731 rather than records of incorrectly identified species becoming entrenched in the literature. Such

732 approaches are valid where the objective of management is to protect reef integrity by ensuring

733 resilience of the coral assemblage at a functional level. 
735 Inferring spawning and timing of sampling: Sampling of the dominant corals must take place

736

737

738

739

740

741

742

743

744

745

746

747

748

749

750

751

752

753

754

755

756

757

758

759

760

761

762 throughout the potential reproductive seasons in order to determine the relative magnitude of reproductive output throughout the year. A key factor in the logical process of determining whether or not spawning has taken place is the construction of a series of data points through time that demonstrates the development of gametes and their subsequent disappearance after spawning. Oogeneic cycles in spawning corals take several months, so in species know to spawn biannually (March, October) or over a protracted period (September to April) eggs will be present in the population during most months. There is no evidence of corals spawning during winter months, so detailed sampling in this period is not necessary. A sampling program to determine the proportion of species and colonies spawning or releasing planulae throughout the year should, however, span at least nine months from the start of spring to the end of autumn. Preliminary sampling should be conducted monthly, and take into consideration the influence of the lunar cycles. Ideally, sampling on Western Australian reefs should occur approximately one week before the predicted night of spawning, providing the greatest amount of information on the timing of spawning based on characteristics of gamete development; more than a week and eggs may not yet be pigmented, while less than a week the chances of missing an early spawning increases. The optimal time of sampling will depend on the assemblage. The presence of mature (pigmented) eggs or larvae (in brooding species), and fully developed sperm, followed by their subsequent disappearance, is the best basis for making strong inferences about the timing of spawning. It is important to note that in many corals, particularly the Acroporidae, eggs may not be pigmented more than two weeks prior to spawning and that unpigmented eggs may also be spawned, highlighting the need for large sample sizes and for sampling to be conducted following spawning events. In other taxa, particularly some Faviidae, eggs may be pigmented for two months or more before spawning.

A single annual sample is a weak basis for inference, particularly when spawning is split or staggered, for species that have protracted spawning seasons, or for brooding corals. It is vital that accurate records of the exact timing of sampling are reported as metadata, in order for clear conclusions to be drawn regarding the timing of spawning based on sequential sampling. 
763 In addition to re-sampling the assemblage through time, tagged colonies would ideally be

764 resampled to strengthen inferences about the time(s) of spawning. This eliminates doubt about

765 whether the presence or absence of gametes is due to a spawning event, or due to variation in the

766 timing of spawning among colonies within a population; it is particularly useful for species that

767 spawn biannually. Consideration must obviously be given to the number of samples that can be

768 taken from a single colony, so as not to cause significant stress and divert energy investment

769 away from reproduction. We suggest that samples from individual colonies are therefore taken

770 strategically, according to the wider pattern identified in the population from which random

771 samples are also taken. For example, sampling an individual colony to determine whether it

772 participates in both a spring and autumn spawning, or in both months of a split spawning, rather

773 than during many months of the year.

774

775 Sample size: Sample sizes must be adequate for the purposes of the study and to account for the 776 background variation in reproduction among species within the community, among conspecific

777 colonies during a year, and among years. If all colonies are reproducing and spawn during the

778 same month, then the level of replication required is small - but considerable sampling is first

779 required to establish this trend and it is uncommon for many species on most reefs. Relying on a

780 fixed sample size for all species can become problematic when colonies spawn during different

781 months, different seasons, if stressed colonies are not reproducing, if they have separate sexes, or

782 if spawning during a year is split. Simulations carried out to assess the power of sampling to

783 detect reproductively mature colonies in coral communities (Styan \& Rosser 2012) can provide

784 useful guidelines for designing sampling programs, after the underlying assumptions have been

785 reviewed and the background variance established in the context of the assumptions of the

786 simulation. The required replication can range from a few colonies per species when all spawn

787 synchronously over a few nights each year, to many more colonies for assemblages with mixed

788 patterns of reproduction during some years. For example, on a reef when $30 \%$ of the assemblage

789 is spawning in spring, many colonies per species will need to be sampled following the full

790 moon in October during a year of split-spawning (after the October spawning) so as not to

791 underestimate the significance of the event, especially if a proportion of colonies are not

792 reproducing due to environmental stress. Otherwise, insufficient sampling would not identify the 
793 period as important and it may not be investigated in subsequent years when spawning was not 794 split and colonies not stressed.

795 It is important to note that the absence of eggs in a colony provides few insights into broader 796 patterns of reproduction, further highlighting the need for sufficient replication. At least 10 or 797 more colonies per species are therefore needed for adequate quantification of reproductive 798 patterns on WA reefs that do not mass spawn during a single month each year - however, the 799 replication required on each reef can only be determined after background variation in space and time are first established. We argue that for most WA reefs it is better to first sample the most

801

802

803

804

805

806

807

808

809

810

811

812

813

814

815

816

817

818

819

820

821 abundant species rigorously to determine their pattern of reproduction, rather than sample most species within low replication. Additionally, within colonies not all polyps may be reproductive, so multiple samples from single colonies are advisable. For example, where both in situ and microscopic examination of eggs are used to infer times of spawning in certain coral species (e.g. staghorn Acropora), eggs may be observed in one method but not the other.

Use of existing data and streamlining of sampling: Studies based on the sampling design principles above are rare, not only in WA but globally due to logistical demands. However, they are necessary for environmental managers because there is insufficient knowledge of the underlying reproductive biology of seasonality and within-population synchrony in coral species at any given location. Where there is well documented information on seasonality and synchrony, sampling may be streamlined. For example, when the species' annual gametogenic cycle has been described and it has been shown that the population spawned with virtually $100 \%$ synchrony during one lunar period of the year, sampling could be conducted immediately before and after the predicted spawning window. However, for most species of coral in WA such information is lacking, making more extended sampling periods necessary.

Once the community has been defined and the experimental design confirmed, methods that can be used to determine the time of spawning or planulae release include: spawning observations, recruitment to artificial substrata, in situ examination of gametes, microscopic examination of gametes (immediate and preserved), and histological examination of gametes. The most appropriate method depends on the question to be addressed, the region in which the reefs are 
822 found and species being investigated, but a rigorous assessment usually combines multiple

823 approaches.

824

825 Direct observations: Direct observations to establish the date and time of spawning include

826 those made of colonies in situ or in aquaria (e.g. Babcock et al. 1994). In situ observations are

827 the most reliable way to confirm spawning, but are rarely conducted because the logistic

828 difficulties limit replication. The most useful way to apply in situ spawning observations is

829 therefore to combine them with data from previous reef surveys and in situ observation of

830 gamete development (see below). Aquarium observations present similar logistical issues, and

831 inflict some level of stress on colonies that potentially alters their time of spawning. The

832 approach has been used more successfully in brooding corals kept in aquaria for several months,

833 with the dates of planula release around lunar phases determined each day with the use of planula

834 collectors (e.g. Richmond \& Jokiel 1984, Jokiel et al. 1985).

835 Another observational method used to provide information on the timing of spawning in coral

836 communities is visual surveys for coral spawn slicks, usually the morning after a spawning

837 event. While this method is useful for establishing that some spawning has occurred, the

838 approach cannot provide information on the scale of the spawning and the origin of the slicks is

839 unknown; the absence of a slick obviously provides no evidence of spawning having not

840 occurred. While all of these methods provide information about the time of spawning in a sub-set

841 of species, they alone are not sufficient to establish the community-wide patterns of reproductive

842 seasonality required for the purposes of managing environmental impacts.

843

844 Coral recruitment: Coral recruitment surveys can be used to inform the general timing of peaks

845 in reproduction (months/seasons) (Wallace \& Bull 1982) but they do not precisely describe

846 temporal variation in peaks in reproduction. This is in part because pre-settlement larval periods

847 vary among coral, particularly spawning and brooding corals, and artificial substrata must be

848 deployed and retrieved in a set period ( $\approx$ few weeks) before and after each spawning; the period

849 before is required to pre-condition substrata with algal communities and the period after is

850 required for larval metamorphosis and calcification to occur. Deploying and retrieving substrata

851 each month is logistically difficult and provides indirect, and relatively imprecise, information 
852 about coral reproduction. A more precise identification of spawning times is usually required by

853 environmental managers. The link between coral reproduction and recruitment can also be

854 decoupled by unknown rates of larval mortality, current speeds and directions (Caley et al. 1996;

855 Edmunds et al. 2010; Hughes et al. 2000) and recruitment provides retrospective rather than

856 predictive insights into the times of reproductive output.

857

858 In situ examination of eggs: In situ examination of eggs is the most common and perhaps useful 859 means of determining times of spawning, provided certain criteria are met. If knowledge of the 860 proportion of colonies participating in a spawning event is required it is vital to know whether 861 the species are hermaphroditic or gonochoric (separate sexes), as eggs will obviously be absent 862 from male colonies. Eggs of gonochoric species are often small and relatively colourless 863 (Harrrison et al. 1990). Even where gonochoric species produce large coloured eggs, testes will 864 remain colourless or white and difficult to distinguish from the white skeleton of a coral 865 fragment. The sex ratio of gonochoric species must be known if the presence of mature 866 (pigmented) eggs in colonies is to be used to infer the proportion spawning. Thus, in-situ visual 867 examination of gonochoric species is more difficult and likely to lead to incorrect conclusions. It 868 is also vital not to sample the sterile tips or the edges of a colony, which have grown subsequent 869 to the initiation of gametogenesis in the rest of the colony (Oliver 1984; Wallace 1985).

870 Furthermore, is it very important to examine multiple polyps within each sample, and multiple 871 samples from each colony, as some polyps may be sterile or have low fecundity. These points 872 apply to whatever method of oocyte examination is to be employed.

873 In situ examination of eggs is most useful for branching corals that have large $(\approx>0.5 \mathrm{~mm})$

874 pigmented oocytes prior to $(<2$ weeks) spawning that can be easily identified in the field (e.g.

875 Acropora spp.). Colonies are generally examined in situ several days prior to the predicted dates 876 of spawning. Maturity is examined in the field by breaking off coral sections to expose oocytes 877 (Harrison et al. 1984), and several sections should be examined if eggs are not initially observed. 878 Oocyte pigmentation is often used as an indication of maturity and timing of imminent 879 spawning. Egg colour varies with developmental stage from small unpigmented eggs (indicating 880 spawning is still some months away), to large pigmented eggs. Importantly, the size of mature 881 eggs and the degree and colour of pigmentation varies among species; when mature Acropora 
882 eggs are typically pink or red, whereas the Faviidae may be blue or green, the Montipora may be

883 brown due to the presence of zooxanthellae, while other species may have cream eggs when 884 mature (Babcock et al. 1986; Harrison et al. 1990; Heyward \& Collins 1985; Shlesinger et al. 885 1998). In Acropora, pigmentation may not occur until two weeks or less before spawning, in 886 some Faviidae eggs may be pigmented as much as two months before spawning, and species 887 such as Acropora and massive Porites have been observed to spawn unpigmented eggs (Babcock 888 et al. 1986; Harrison et al. 1984; Harrison et al. 1990; Mangubhai \& Harrison 2007; Stoddart et 889 al. 2012), all complicating the use of egg colour as an indicator of imminent spawning. While in 890 situ visual observations have led to many useful inferences about the timing of spawning in coral 891 communities, they can be ambiguous and are best used as part of a sampling program that also 892 uses microscopic examination of eggs, and ideally the sequential sampling of tagged colonies. 893 Spawning times should also be confirmed by the disappearance of eggs from colonies following 894 the predicted date of spawning.

895

896

897

898

899

900

901

902

903

904

905

906

907

908

909

910

911

Microscopic examination of gametes: In situ examination of polyps is well supported by microscopic examination of the samples on the same day. Such examinations should be conducted on broken sections of coral under a dissecting microscope or with a hand lens, and can reveal gonads that were not visible underwater. This is particularly useful for species with small polyps and gonads, or those with a low fecundity (e.g. branching Acropora). Inferences about the times of spawning are also improved by investigating the developmental stages of testes. When testes are prepared and examined with a compound microscope $(40 \times$ objective $)$, sperm shape and motility can be observed. Testes enlarge markedly and sperm develop tails during the last month before spawning. Sperm heads remain spherical until the last one to two weeks before spawning, when they will become cone or acorn shaped, and a high degree of sperm motility occurs a few days before spawning (Harrison et al. 1984). Microscopic examinations are more time consuming, but always more reliable and informative than field observations alone.

Microscopic examination of gamete development can also be conducted on well preserved samples, but only after the sample has been decalcified with acid. Egg colour and shape are not retained following preservation and it is not possible to discern aspects of sperm morphology or behaviour. Where the dimensions of mature eggs or testes are known for species being sampled, 
912 measurements of their size can be can be used to make inferences about the likely time of

913 spawning. Several studies have quantified the size of eggs within replicate colonies of a species

914 at the time of spawning, and there can be variation in egg sizes within colonies and among

915 conspecific corals (Gilmour et al. 2016; Heyward \& Collins 1985; Mangubhai 2009; Mangubhai

916 \& Harrison 2007; Stobart et al. 1992; Wallace 1985; Wallace 1999). Egg size prior to spawning

917 can also vary considerably from year to year, and is not a reliable metric alone for determining

918 the month of spawning. Therefore, egg size can be used to estimate level of maturity and as an

919 indicator of spawning with accuracy of perhaps two months, but probably not for a single month

920 or less. Consequently, investigation of the preserved gametes is particularly useful for tracking

921 their development over several months leading up to a spawning event, but to determine the

922 month(s) spawning also requires in situ and microscopic examination as part of the sequential

923 sampling program.

924

925 Histological examination of gametes: Histology is used for corals that are not well suited to

926 field examinations, usually due to their morphology and their having small polyps and eggs that

927 are not easily visible with the naked eye (i.e. massive Porites, Pavona). Often these are also

928 gonochoric species with separate male and female colonies, for which histology provides the

929 only approach to describing the development of testes prior to spawning. This method is also

930 commonly employed to assess reproductive status of brooding corals and the presence of planula

931 larvae. Preparation for histological examination is time consuming and costly, and usually

932 involves decalcifying tissue, dehydration and fixing of samples in wax, and then sectioning and

933 mounting tissue to slides. Egg and testis development or presence of planula larvae can then be

934 assessed using previous work as guides (Szmant-Froelich et al. 1985; Vargas-Ângel et al. 2006).

935 The development and growth of gonads and gametes can be tracked by measuring changes in

936 size as well as morphological developmental features like sperm shape through time. As with in

937 situ examination of gonads, sperm development stage is a particularly useful indicator of

938 maturity and imminent spawning. Gamete development stages are frequently used in describing

939 the reproductive status of corals sampled using histological methods, and also occasionally for

940 microscopic examinations of freshly sampled tissues. Gamete development staging should be

941 done with reference to published and accepted staging criteria available in the peer reviewed 
942 literature, and clearly defined so that the unambiguous interpretation of staging by others will be 943 possible.

944

945 Complementary methods: The most informative studies of coral reproduction involve

946 sequential sampling of colonies using a combination of complementary methods. For example,

947 determining the times of spawning may involve monthly examination of eggs in preserved

948 samples. As eggs approach a size in which spawning is likely, then preserved samples may be

949 supplemented or replaced by in situ and microscopic examination of egg size and pigmentation,

950 as well as the size of testes and the stages of sperm development. When the night of spawning is

951 predicted within a given month, the in situ and microscopic examinations of eggs and sperm are

952 continued on a daily basis around the predicted nights of spawning, possibly supplemented by in

953 situ observations of spawning and evidence of spawn slicks the following day. On all reefs, a

954 proportion of species and colonies typically spawn over several nights, so continued sampling is

955 required to quantify the proportion of colonies without eggs and to identify the main night of

956 mass spawning within a period.

957 Great care should be taken to correctly record metadata and to correctly identify the main night

958 of spawning relative to the full moon, particularly to note instances when split-spawning has

959 occurred. Split-spawning typically occurs every few years and can occur over consecutive years, 960 and not recognising the phenomenon has biased the existing data for Western Australian reefs.

961 Also, supplementing these methods with tagged colonies that are sampled periodically through

962 time will give a better indication of whether split-spawning has occurred, whether assemblages

963 spawn biannually or over a protracted period, or whether species have overlapping gametogenic

964 cycles (e.g. Turbinaria). For gonochoric species with small polyps and gametes, or brooding

965 corals, this sampling approach will likely involve the use of histological analyses as well as in

966 situ and microscopic methods. These approaches are examples of applying multiple

967 complimentary methods, but the best approach will depend on the aims of the study, the region, 968 habitat, and species being investigated.

969

970 Quantifying temporal variation in coral reproductive output 
971 Since the discovery of mass coral spawning on the Great Barrier Reef, the phenomenon of mass-

972 or multi-specific spawning has been documented at an increasing number of reefs around the

973 world (Baird et al. 2009; Harrison 2011). In many of these studies sampling has been conducted

974 around the main periods of spawning on the nearest reefs and focused on species of Acropora,

975 which are most likely to spawn synchronously and are easiest to sample. The results have

976 established the timing and participation by species in the primary spawning event(s). However,

977 fewer studies have provided detailed information about cycles of gametogenesis in spawning

978 corals and planulation in brooding corals during other months of the year, despite a proportion of

979 colonies of some of the most common species not participating in the primary spawning event(s)

980 on a reef. For example, on inshore reefs of Western Australia's Pilbara region the Acropora may

981 be relatively rare ( $\approx 5 \%$ by cover), whereas species of massive Porites, Turbinaria and Pavona

982 that have novel cycles of reproduction may be among the most common (10-20\% by cover)

983 (Baird et al. 2011; Stoddart et al. 2012). Even on reefs where the Acropora are among the most

984 common genera ( $25 \%$ by cover), such as on the oceanic reefs of the Kimberley, other common

985 groups of corals such as the massive Porites (20\%), Isopora (14\%) and Pocilloporidae (10\%)

986 also have different reproductive modes or cycles.

987 An accurate assessment of the significance of periods of reproductive output requires knowledge

988 of the proportion of colonies within each species releasing gametes or larvae during many

989 months of the year. Additionally, several years of data with varying environmental conditions are

990 required to understand the drivers of inter-annual variation, such as whether a low participation

991 in a spawning event was due to environmental stress or split-spawning. Without these

992 comprehensive data, surveys during previous years provide few insights into future spawning

993 events, requiring substantial sampling effort to be repeated prior to every period of interest. In

994 the worst instances, focusing only on the participation by species in a single month risks

995 perpetuating a paradigm of mass spawning or missing a significant period of reproductive output.

996 A lack of accurate and unbiased information about times of reproductive output by coral

997 communities impedes management initiatives aimed at reducing pressures to their early life

998 history stages. Managers would ideally be provided with quantitative estimates of the

999 reproductive output during different weeks, and even nights of the year, and its contribution to

1000 the long-term maintenance of populations. Obtaining this knowledge is logistically impossible 
1001 until methods are developed that can easily quantify larval production, survival, connectivity, 1002 and per capita rates of recruitment per adult, for the most abundant species within a community. 1003 However, with far less effort it is possible to obtain relative estimates of reproductive output for 1004 coral communities in different months of the year. Mass spawning was originally defined as 1005 '...the synchronous release of gametes by many species of corals, in one evening between dusk 1006 and midnight...' (Willis et al. 1985), taking place within a mass spawning period of up to a week 1007 following full moon on the Great Barrier Reef. There has since been debate about what 1008 constitutes a 'mass spawning' or a 'multi-specific spawning' on a reef, and a quantitative 1009 estimate of spawning synchrony has been developed (Baird et al. 2009) to assess biogeographic 1010 variation in spawning synchrony among species. Here we consider one approach to quantifying 1011 the significance of periods of reproductive output for coral communities on a reef, which 1012 combines the relative abundance of coral groups with the proportion spawning or releasing 1013 larvae during different months.

1014 To apply information on reproductive synchrony to the management of ecological processes, 1015 such as reproduction and recruitment in coral communities, it is necessary to quantitatively 1016 weight this information according to community composition. Community composition on a reef 1017 varies considerably among habitats (lagoon, reef flat, reef crest, reef slope) and among sites 1018 within these habitats, particularly on inshore reefs. The abundance of corals with different cycles 1019 and modes of reproduction also vary among these habitats and sites, so careful consideration 1020 must be made of the assemblage of corals that best characterises the reef when assessing its times 1021 of reproductive output (or the assemblage for which reproductive information is required). Here 1022 we define the community based on percentage cover data, which is regularly collected during 1023 monitoring programs across habitats and replicate sites. These data provide a less biased sample 1024 of the community composition than is often obtained during reproductive surveys and can 1025 provide unexpected insights into which coral groups are most common and whether their 1026 patterns of reproduction are well known. For example, knowledge of coral reproduction is often 1027 for the most conspicuous and easily sampled species of Acropora, whereas little reproductive 1028 data may exist for other species of spawning (e.g. Montipora, Porites) and brooding corals (e.g. 1029 Isopora, Seriatopora) that may have a similar relative abundance on a reef. 
1030 Once the community composition has been quantified, a decision must be made about whether 1031 all taxa are to be included, or whether sampling effort can be reduced by excluding the rare

1032

1033

1034

1035

1036

1037

1038

1039

1040

1041

1042

1043

1044

1045

1046

1047

1048

1049

1050

1051

1052

1053

1054

1055

1056

1057

1058

1059

corals. Although there are typically over tens of genera and hundreds of coral species on tropical coral reefs, many species are rare. For example, on Kimberley oceanic reefs there are over 35 genera and 300 species of hard corals, but 10 genera contribute approximately $85 \%$ of the coral cover and five genera contribute approximately $65 \%$ of the cover. On reefs with less diversity, comparatively few species may contribute much of the coral cover. A 'community' may therefore be defined by the corals that make up most (e.g. $>80 \%$ ) of the total coral cover. An alternative to using a threshold of relative abundance is applying multivariate analyses to quantify the coral groups that best characterise, or distinguish, community structure through space and time, depending on the objectives of the study. Focusing on the detailed patterns of reproduction in the dominant species on a reef significantly reduces the sampling effort required to quantify temporal variation in reproductive output, as finding and sampling rare species with sufficient replication is most time consuming. Care must obviously be taken in deciding the threshold for including dominant species in a 'community' and the means by which they are categorised (e.g. family, genus, species, growth form), which will need to be reviewed as communities change and as more reproductive data are obtained.

Further confounding assessments of the significance of reproductive periods on a reef is the identification of coral species. The issue is improved by considering only the most common species, but even these can be very difficult to distinguish. Variation in physical conditions among reefs and habitats, hybridization, reproductive isolation, and cryptic speciation make it impossible to correctly identify all of the colonies sampled during extensive reproductive surveys, and very few people are capable of correctly identifying most colonies correctly in situ. For example, many species of Porites, Faviidae, Montipora and Acropora are common on most tropical coral reefs, but within each of these taxa are many species easily confused in situ, even by experts. Errors in the identification of species will affect estimates of the number of species and the proportion of their colonies participating in a spawning, yet this can be the criteria by which the significance of spawning events is assessed. Inconsistent identification of species likely accounts for some apparent discrepancies in the times of spawning by species within regions of Western Australia presented here. 
1060 It is also impossible to correctly identify all species when quantifying the composition of coral 1061 communities in monitoring programs, particularly from photographic or video stills. Broader 1062 taxonomic, morphological and life history groups are usually used in this context. Thus, when 1063 quantifying the significance of spawning events for coral communities, errors can be avoided and 1064 efficiency increased by grouping some species to a higher taxonomic level (Genera/Family), but 1065 also distinguishing these according to growth form (e.g. branching, corymbose, encrusting; 1066 Wallace 1990, Veron 2000) and reproductive mode (spawner, brooder; Harrison and Wallace 1067 1990, Baird et al. 2009). The approach is obviously not needed for species that are abundant 1068 and/or functionally important on a reef and easily identified (e.g. Isopora brueggemanni, 1069 Seriatopora hystrix, Diploastrea heliopora).

1070 Once the community of interest is defined and the relative cover of coral groups determined, the 1071 patterns of reproduction must be accurately quantified (see Section 3). The approach suggested 1072 here is to combine the community abundance and reproductive data to quantify relative estimates 1073 of reproductive output by the community throughout the year; it is therefore necessary to have 1074 both types of data for the same groups of corals. For example, in a hypothetical coral assemblage 1075 of two species, species A makes up 20\% (relative) of the total coral cover and spawns only 1076 during October, and species B makes up 80\% of the coral cover and spawns during March. 1077 Reproductive output for the community is therefore 20\% during October and 80\% in March. In 1078 this example, both species reproduce exclusively during a single month, whereas communities characteristically have species that spawn during two or more months a year, due to phenomena such as split-spawning, asynchronous spawning and within-population biannual spawning. Additionally, brooding corals release larvae over several months within a year. Here we use available data to apply the approach at two hypothetical reefs with contrasting coral assemblages and patterns of reproduction (Figure.2), which are similar to those at some oceanic and inshore reefs of Western Australia. The method for calculating reproductive output during each month is simple (Supplementary Table 4), but considerable sampling effort is required to produce accurate estimates of community composition and the proportion of colonies within each taxa reproducing each month (Section 3, Supplementary Table 4). Quantifying the proportion reproducing each month will usually require monthly sampling, or at least bimonthly, although less effort may be 1089 required after several years under a range of conditions and depending on the methods used. 
1090 In a hypothetical example for an oceanic and inshore reef at north-western Australia, the monthly 1091 reproductive output differed according to their community composition and the cycles of 1092 reproduction within and among coral taxa (Figure 3 ). The main month of reproductive output at both reefs was March, but with more synchronous spawning in March at the oceanic reef and more protracted spawning over March and April at the inshore reef. At both reefs, over 40\% of the communities reproductive output occurred during other months, but for different reasons. The oceanic reef had a higher $(\approx 20 \%)$ reproductive output during spring (October/November) and particularly October than at the inshore reef $(\approx 8 \%)$, due to a higher number of species 1098 spawning biannually, a higher abundance of Acropora, and a tendency for spawning to be more synchronous during a single month. There was a much higher reproductive output in December $(22 \%)$ on the inshore reef, due to the abundance many massive Porites that spawn predominantly in December. During several other months of the year reproductive output was higher on the oceanic reef, due mainly to the many massive Porites spawning and brooding Isopora releasing larvae from spring to autumn. In contrast, the brooding corals in this example were rare on the inshore reef and the spawning over several months was restricted to the Turbinaria. These estimates of reproductive output for the oceanic reef and the inshore reef are hypothetical, intended only to provide a worked example. 

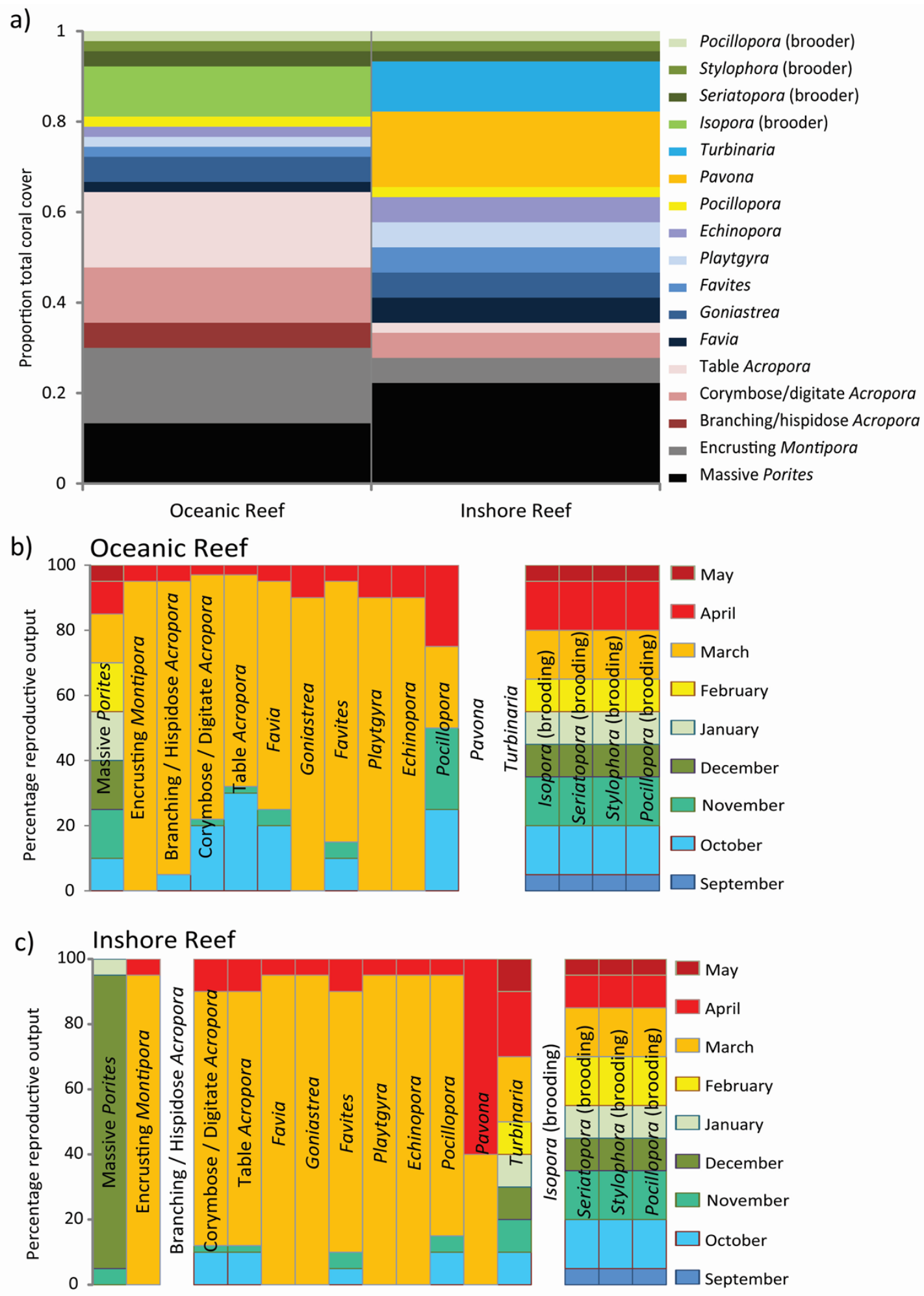
Figure 2. Variation in composition and times of reproduction at Western Australian Reefs. a) Proportional contribution of coral groups to total coral cover at a hypothetical oceanic and inshore reef, and the percentage reproductive output (spawning, planula release) through the year at the b) oceanic and c) inshore reef. In this example, Povona and Turbinaria were absent from the oceanic reef and Isopora absent from the inshore reef.

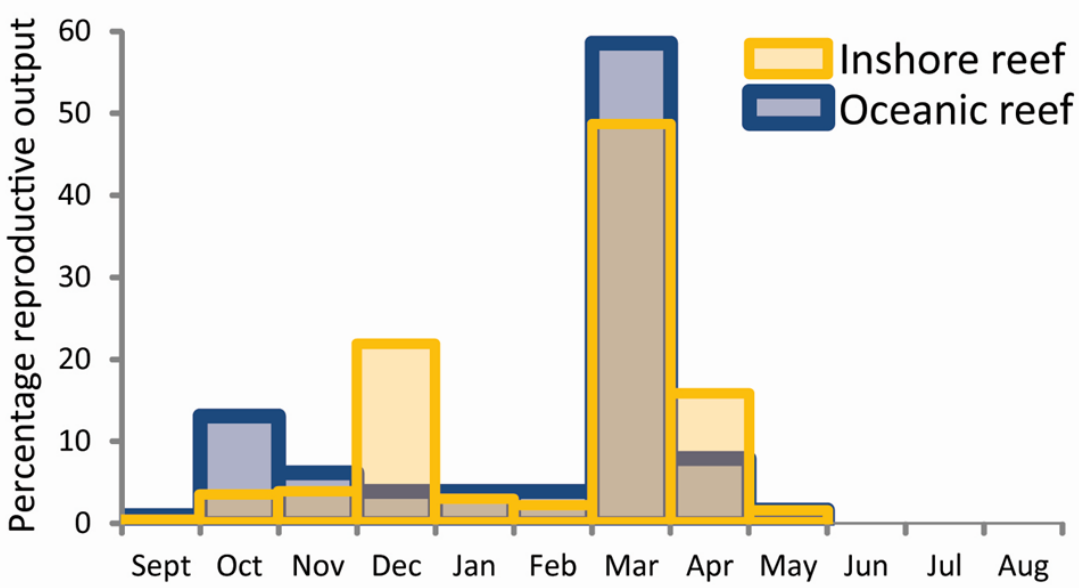

Figure 3. Percentage reproductive output during each month on a hypothetical oceanic and inshore reef at north-western Australia. Calculations are based on the relative abundance of coral groups within the community and the proportion reproductive output for spawning and brooding corals during each month of the year (Fig. 3; Supplementary Table 4).

This is one of several possible approaches to quantifying temporal variation in reproductive output for an entire community throughout the year, intended to aid management decisions. The approach is aimed at identifying the months in which significant reproductive output occurs at the scale of the entire community, and more detailed temporal sampling within these months is required to determine the nights of spawning and planula release relative to the phases of the moon. In the context of managing environmental impacts, the approach presented here has several limitations. Most significantly, by considering the reproductive output of the community as a whole, it does not sufficiently recognise the significance of periods of reproductive output by functionally important species with unique cycles of reproduction. For example, massive Porites on inshore reefs that spawn predominantly just a few nights after the full moon in December (Stoddart et al. 2012), or species on the oceanic reefs that may spawn exclusively during spring (Supplementary Table 4). Additionally, brooding corals may have a negligible (e.g. 
$1122<20 \%$; Supplementary Table 4) proportion of planula release during the month and particularly

1123 main night of mass spawning on a reef, occurring around the full moon over several other

1124 months through the year.

1125 Importantly, the proportion of reproductive output each month will vary among years according

1126 to changes in community structure and particularly the occurrence of split-spawning or

1127 environmental stress. Consequently, several years of data collection are required to obtain a

1128 reasonable understanding of reproduction on the reef before sampling effort can be reduced. For

1129 example, it may be concluded incorrectly that reproductive output was not significant during

1130 March, the usual month of mass-spawning by coral on most Western Australian reefs, if

1131 spawning was split (March/April) or because environmental stress (e.g. poor water quality,

1132 cyclone damage or mass-bleaching) precluded reproduction. Another limitation of this approach

1133 is that the temporal resolution is presented to the calendar month, with the assumption that

1134 spawning occurs approximately one week after the full moon, whereas reproductive output in

1135 some spawning corals (e.g. Faviidae at Ningaloo Reef) and many brooding corals are likely to

1136 occur around the new moon. Furthermore, affording protection to only the main month of mass

1137 spawning and not in other months may have unforeseen consequences, such as affecting

1138 connectivity between reefs following spawning events in which oceanographic currents differ

1139 (Gilmour et al. 2009), or by reducing the genetic diversity of new recruits. This highlights the

1140 need to consider reproductive output for the entire community in the context of more detailed

1141 reproductive data for abundant or functionally important species of corals. Assessing the

1142 strengths and weaknesses of the approach requires a dedicated sampling design, on reefs with

1143 different coral communities through several years of environmental conditions. Other, and

1144 possibly better, approaches exists, however we present one here to formally introduce and

1145 hopefully build the concept. 
1147

1148

1149

1150

1151

1152

1153

1154

1155

1156

1157

1158

1159

1160

1161

1162

1163

1164

1165

1166

1167

1168

1169

1170

1171

1172

1173

1174

1175

\section{REFERENCES}

Abdo DA, Bellchambers LM, Evans SN, and Evans S. 2012. Turning up the heat: Increasing temperature and coral bleaching at the high latitude coral reefs of the Houtman Abrolhos Islands. Plos one 7:e43878.

Alino PM, and Coll JC. 1989. Observations of the synchronized mass spawning and postsettlement activity of octocorals on the Great Barrier Reef, Australia: Biological Aspects. Bulletin of Marine Science 45:697-707.

Ayre DJ, and Resing JM. 1986. Sexual and asexual production of planulae in reef corals. Marine Biology 90:187-190.

Babcock RC. 1991. Comparative demography of three species of scleractinian corals using ageand size-dependent classifications. Ecological Monographs 61:225.

Babcock RC, Bull GD, Harrison PL, Heyward AJ, Oliver JK, Wallace C, and Willis BL. 1986. Synchronous spawning of 105 scleractinian coral species on the Great Barrier Reef Australia. Marine Biology 1986. 379-394.

Babcock RC, Willis B, and Simpson CJ. 1994. Mass spawning of corals on a high latitude coral reef. Coral Reefs 13:161-169.

Baird AH, Blakeway DR, Hurley TJ, and Stoddart JA. 2011. Seasonality of coral reproduction in the Dampier Archipelago, northern Western Australia. Marine Biology 158:275-285.

Baird AH, Guest JR, and Willis BL. 2009. Systematic and biogeographical patterns in the reproductive biology of scleractinian corals. Annual Review of Ecology and Systematics 40:551-557.

Baird AH, Marshall PA, and Wolstenholme JK. 2002. Latitudinal variation in the reproduction of Acropora in the Coral Sea. 9th International Coral Reef Symposium. Bali, Indonesia. p 385-389.

Bancroft KP. 2009. Mapping the coral reef communities of Shark Bay marine protected areas: data collected during the February 2008 field survey. Marine Science Program Data Report Series 3. Perth: Department of Environment and Conservation, Kensington, WA. $\mathrm{p} 45$. 
1176

1177

1178

1179

1180

1181

1182

1183

1184

1185

1186

1187

1188

1189

1190

1191

1192

1193

1194

1195

1196

1197

1198

1199

1200

1201

1202

1203

1204

1205

1206

Bassim KM, Sammarco PW, and Snell TL. 2000. Effects of temperature on success of (self and non-self) fertilization and embryogenesis in Diploria strigosa (Cnidaria, Scleractinia). Marine Biology 140:479.

Berry P. 1993. Marine Faunal Surveys of Ashmore Reef and Cartier Island NW Australia. Records of the Western Australian Museum Supplement No. 44.

Berry PF, and Marsh LM. 1986. Faunal Surveys of The Rowley Shoals, Scott Reef and Seringapatam, NW Australia. Records of the Western Australian Museum Supplement No. 26.

Blakeway D, and Radford B. 2004. Scleractinian corals of the Dampier Port and inner Mermaid Sound: species list, community composition and distributional data. Corals of the Dampier Harbour: their survival and reproduction during the dredging programs of 2004.

Caley MJ, Carr MH, Hixon MA, Hughes TP, Jones GP, and Menge BA. 1996. Recruitment and the local dynamics of open marine populations. Annual Review of Ecology and Systematics 27:477-500.

Carson HS, and al e. 2010. Reproductive Timing Alters Population Connectivity in Marine Metapopulations. Current Biology 20:1926-1931.

Cary J. 1997. Baseline studies and monitoring of visitor sites in the Shark Bay Marine Park, Shark Bay World Heritage Area and Hamelin Pool Marine Nature Reserve, Shark Bay marine reserves monitoring programme: final report MMSP/MW/SBMP-4/1997. Perth: Commonwealth Department of Tourism and Department of Conservation and Land Management.

Crane KR. 1999. Reproductive Biology of Scleractinian Coral at Rottnest Island, Western Australia.Honours. Murdoch.

Cresswell G. 1996. The Leeuwin current near Rottnest island, western Australia. Marine and Freshwater Research 47:483-487.

D'Adamo N, Fandry C, Buchan S, and Domingues C. 2009. Northern Sources of the Leeuwin Current and the "Holloway Current" on the North West Shelf. Journal of the Royal Society of Western Australia 92:53-66.

Dai C, Soong K, and Fan T. 1992. Sexual reproduction of corals in northern and southern Taiwan. Proc 7th int coral Reef Symp. p 448-455. 
1207 Dai CF, Fan TY, and Yu JK. 2000. Reproductive isolation and genetic differentiation of a 1208 scleractinian coral Mycedium elephantotus. Marine Ecology Progress Series 201:179$1209 \quad 187$.

1210 Dinsdale EA, and Smith L. 2004. Broadscale survey of coral condition on the reefs of the Easter Group of the Houtman Abrolhos Islands. Australian Institute of Marine Science.

Done TJ. 1987. Simulation of the effects of Acanthaster planci on the population structure of massive corals in the genus Porites: Evidence of population resilience? Coral Reefs 6:7590.

Done TJ, and Potts DC. 1992. Influences of habitat and natural disturbances on contributions of massive Porites corals to reef communities. Marine Biology 114:479-493.

Done TJ, Williams DM, Speare P, Turak E, Davidson J, De Vantier LM, Newman SJ, and Hutchins JB. 1994. Surveys of coral and fish communities at Scott Reef and Rowely Shoals. Report to the Browse Joint Venture Partners. Perth: Australian Institute of Marine Science. $\mathrm{p} 195$.

Edmunds PJ. 2005. The effect of sub-lethal increases in temperature on the growth and population trajectories of three scleractinian corals on the southern Great Barrier Reef. Population Ecology 146:350-364.

Edmunds PJ, Leichter JJ, and Adjeroud M. 2010. Landscape-scale variation in coral recruitment in Moorea, French Polynesia. Marine Ecology Progress Series 414:75-89.

Fadlallah YH. 1983. Sexual reproduction, development and larval biology in Scleractinian corals. A review. Coral Reefs 2:192-150.

Fan TY, and Dai CF. 1995. The reproductive ecology of the scleractinian coral Echinopora lamellosa in northern and southern Taiwan. Marine Biology 123:565-572.

Fellegara I, Baird A, and Ward S. 2013. Coral reproduction in a high-latitude, marginal reef environment (Moreton Bay, south-east Queensland, Australia). Invertebrate Reproduction \& Development 57:219-223.

Fong P, and Glynn PW. 1998. A dynamic size-structured population model: Does disturbance control size structure of a population of the massive coral Gardineroseris planulata in the eastern Pacific? Marine Biology 130:663-674.

Fong P, and Glynn PW. 2000. A regional model to predict coral population dynamics in response to El Nino-Southern Oscillation. Ecological Applications 10:842-854. 
1238 Gilmour J. 1999. Experimental investigation into the effects of suspended sediment on

1239

1240

1241

1242

1243

1244

1245

1246

1247

1248

1249

1250

1251

1252

1253

1254

1255

1256

1257

1258

1259

1260

1261

1262

1263

1264

1265

1266

1267 fertilisation, larval survival and settlement in a scleractinian coral. Marine Biology 135:451-462.

Gilmour JP, Baird AH, Pratchett MS, and Smith LD. 2006. The maintenance of populations of mushroom coral Fungia fungites under different disturbance regimes: sexual versus asexual recruitment. Proceedings of the Tenth International Coral Reef Syposium. p 351358.

Gilmour JP, Underwood JN, Howells EJ, Gates E, and Heyward AJ. 2016. Biannual Spawning and Temporal Reproductive Isolation in Acropora Corals. Plos one 11:11(13): e0150916. doi:0150910.0151371/journal.pone.0150916.

Glynn PW, Colley SB, Eakin CM, Smith DB, Cortes J, Gassman N, Guzman HM, Del Rosario JB, and Feingold JS. 1994. Reef coral reproduction in the eastern Pacific: Costa Rica, Panama, and Galapagos Islands (Ecuador): II. Poritidae. Marine Biology 118:191-208.

Glynn PW, Gassman NJ, Eakin CM, Cortes J, Smith DB, and Guzman HM. 1991. Reef coral reproduction in the eastern Pacific: Costa Rica, Panama, and Galapagos Islands (Ecuador). Marine Biology 109:355-368.

Griffith JK. 2004. Scleractinian corals collected during 1998 from the Dampier Archipelago, Western Australia. In: Jones DS, ed. Report of the Results of the Western Australian Museum/Woodside Energy Ltd Partnership to Explore the Marine Biodiversity of the Dampier Archipelago Western Australia 1998-2002 Records of the Western Australian Museum No 66. Perth: Western Australian Museum, 101-120.

Guest JR, Baird AH, Goh BPL, and Chou LM. 2005a. Reproductive synchrony in an equatorial assemblage of scleractinian corals. Coral Reefs 24:112-116.

Guest JR, Baird AH, Goh BPL, and Chou LM. 2005b. Seasonal reproduction in equatorial reef corals. Invertebrate Reproduction \& Development 48:207-218.

Harriott VJ. 1983a. Reproductive ecology of four scleractinian species at Lizard Island, Great Barrier Reef. Coral Reefs 2:9-18.

Harriott VJ. 1983b. Reproductive seasonality, settlement, and post-settlement mortality of Pocillopora damicornis (Linnaeus), at Lizard Island, Great Barrier Reef. Coral Reefs 2:151-157. 
1268 Harriott VJ. 1992. Recruitment patterns of scleractinian corals in an isolated sub-tropical reef

1269

1270

1271

1272

1273

1274

1275

1276

1277

1278

1279

1280

1281

1282

1283

1284

1285

1286

1287

1288

1289

1290

1291

1292

1293

1294

1295

1296

1297

1298 system. Coral Reefs 11:215-219.

Harriott VJ, and Banks SA. 2002. Latitudinal variation in coral communities in eastern Australia: a qualitative biophysical model of factors regulating coral reefs. Coral Reefs 21:83-94.

Harrison P. 1993. Coral spawning on the Great Barrier Reef. Search 24:45-48.

Harrison P, Babcock R, Bull GD, Oliver J, Wallace CC, and Willis B. 1984. Mass spawning in tropical reef corals. Science 223:1186-1189.

Harrison P, Wallace C, and Dubinsky Z. 1990. Reproduction, dispersal, and recruitment of scleractinian corals. Ecosystems of the World: Coral Reefs: Elsevier Publishers New York, 133-207.

Harrison PL. 2008. Coral spawn slicks at Lord Howe Island, Tasman Sea, Australia; the world's most southerly coral reef. Coral Reefs 27:35-35.

Harrison PL. 2011. Sexual reproduction of scleractinian corals. In: Dubinsky Z, and Stambler N, eds. Coral reefs: an ecosystem in transition: Springer Netherlands, 59-85.

Harrison PL, and Ward S. 2001. Elevated levels of nitrogen and phosphorus reduce fertilisation success of gametes from scleractinian reef corals. Marine Biology 139:1057-1068.

Hatcher BG. 1991. Coral reefs in the Leeuwin Current -- an ecological perspective. Journal of the Royal Society of Western Australia 74:115-127.

Heyward AJ, and Collins JD. 1985. Growth and sexual reproduction in the scleractinian coral Montipora digitata (Dana). Australian Journal of Marine and Freshwater Research 36:441-446.

Hughes TP, Baird AH, Dinsdale EA, Moltschaniwskyj NA, Pratchett MS, Tanner JE, and Willis BL. 2000. Supply-side ecology works both ways: The link between benthic adults, fecundity, and larval recruits. Ecology 81:2241-2249.

Humphrey C, Weber M, Lott C, Cooper T, and Fabricius K. 2008. Effects of suspended sediments, dissolved inorganic nutrients and salinity on fertilisation and embryo development in the coral Acropora millepora (Ehrnberg, 1834). Coral Reefs Coral Reefs.

INPEX. 2011. Biological and ecological studies of the Bonaparte Archipelago and Browse Basin. Perth: INPEX - Ichthys Project.

Johannes RE, Wiebe WJ, Crossland CJ, Rimmer DW, and Smith SV. 1983. Latitudinal limits of coral reef growth. Marine Ecology Progress Series 2:105-111. 
1299

1300

1301

1302

1303

1304

1305

1306

1307

1308

1309

1310

1311

1312

1313

1314

1315

1316

1317

1318

1319

1320

1321

1322

1323

1324

1325

1326

1327

1328

Kojis BL. 1986. Sexual reproduction in Acropora (Isopora) species (Coelenterata: Scleractinia) 1. A. cuneata and A. palifera on Heron Island reef, Great Barrier Reef. Marine Biology 91:291-309.

Kojis BL, and Quinn NJ. 1982. Reproductive strategies in four species of Porites (Scleractinia). Proc 4th Int Coral Reef Symp. p 145-151.

Kool JT, Moilanen A, and Treml EA. 2013. Population connectivity: recent advances and new perspectives. Landscape Ecology 28:165-185.

Lough JM, and Barnes DJ. 2000. Environmental controls on growth of the massive coral Porites. Journal of Experimental Marine Biology and Ecology 245:225-243.

Mangubhai S. 2009. Reproductive ecology of the sceractinian corals Echinopora gemmacea and Leptoria phrygia (Faviidae) on equatorial reefs in Kenya. Invertebrate Reproduction and Development 53:67-79.

Mangubhai S, and Harrison P. 2006. Seasonal patterns of coral reproduction on equatorial reefs in Mombasa, Kenya. 10th International Coral Reef Symposium, Okinawa, Japan:106113.

Mangubhai S, and Harrison PL. 2007. Gametogenesis, spawning and fecundity of Platygyra daedalea (Scleractinia) on equatorial reefs in Kenya. Coral Reefs 27:117-122.

Markey KL, Baird AH, Humphrey C, and Negri A. 2007. Insecticides and a fungicide affect multiple coral life stages. Marine Ecology Progress Series 330:127-137.

Marsh L. 2000. Scleractinian corals of the Montebello Islands. In: Berry P, and Wells F, eds. Survey of the marine fauna of the Montebello Islands, Western Australia and Christmas Island, Indian Ocean. Perth: Records of the Western Australian Museum.

McKinney D. 2009. A survey of the scleractinian corals at Mermaid, Scott, and Seringapatam Reefs, Western Australia. Records of the Western Australian Museum Supplement 77:105-143.

Michalek-Wagner K, and Willis BL. 2001. Impacts of bleaching on the soft coral Lobophytum compactum. I. Fecundity, fertilization and offspring viability. Coral Reefs 19:231-239.

Moore JAY, Bancroft KP, and Holley D. 2011. Coral reef communities. In Western Australian Marine Monitoring Program: annual marine protected area condition pressure response report: Shark Bay Marine Park and Hamelin Pool Marine Nature Reserve annual report, 
1329

1330

1331

1332

1333

1334

1335

1336

1337

1338

1339

1340

1341

1342

1343

1344

1345

1346

1347

1348

1349

1350

1351

1352

1353

1354

1355

1356

1357

2011. In: Bancroft K, editor. Perth: Department of Environment and Conservation, Kensington, WA. p 24-35.

Negri AP, and Heyward AJ. 2001. Inhibition of coral fertilisation and larval metamorphosis by tributyltin and copper. Marine and Environmental Research 51:17-27.

Negri AP, Marshall PA, and Heyward AJ. 2007. Differing effects of thermal stress on coral fertilization and early embryogenesis in four Indo Pacific species. Coral Reefs 26:759763.

Oliver JK. 1984. Intra-colony variation in the growth of Acropora formosa : Extension rates and skeletal structure of white (zooxanthellae-free) and brown-tipped branches. Coral Reefs 3:139-147.

Oliver JK, Babcock RC, Harrison PL, and Willis BL. 1988. Geographic extent of mass coral spawning: clues to ultimate causal factors. Proceedings of the Sixth International Coral Reef Symposium, Townsville:803-810.

Penland L, Kloulechad J, Idip D, and van Woesik R. 2004. Coral spawning in the western Pacific Ocean is related to solar insolation: evidence of multiple spawning events in Palau. Coral Reefs 23:133-140.

Richards Z, Garcia R, Wallace C, Rosser N, and Muir P. 2015. A diverse assemblage of reef corals thriving in a dynamic intertidal reef setting (Bonaparte Archipelago, Kimberley, Australia). Plos one 10.

Richards Z, and Rosser N. 2012. Abundance, distribution and new records of scleractinian corals at Barrow Island and Southern Montebello Islands, Pilbara (Offshore) Bioregion. Journal of the Royal Society of Western Australia 95:155-165.

Richards, ZT, Beger, M, Hobbs, J-P, Bowling, T, Chong-seng, K, and Pratchett, M. 2009. Ashmore Reef National Nature Reserve and Cartier Island Marine Reserve Marine Survey 2009. ARC Centre of Excellence for Coral Reef Studies. Produced for the Department of the Environment, Water, Heritage and the Arts. Richards ZT, Sampey A, and Marsh L. 2014. Marine Biodiversity of the Kimberley 1880s-2009. Kimberley marine biota Historical data: scleractinian corals: Records of the Western Australian Museum Supplement 84. p 111-132. 
1358 Richmond RH, and Hunter CL. 1990. Reproduction and recruitment of corals: comparisons

1359

1360

1361

1362

1363

1364

1365

1366

1367

1368

1369

1370

1371

1372

1373

1374

1375

1376

1377

1378

1379

1380

1381

1382

1383

1384

1385

1386

1387

1388 among the Caribbean, the Tropical Pacific, and the Red Sea. Marine Ecology Progress Series 60:185-203.

Sakai K. 1997. Gametogenesis, spawning, and planula brooding by the reef coral Goniastrea aspera (Scleractinia) in Okinawa, Japan. Marine Ecology Progress Series 151:67-72.

Sebens KP. 1983. The larval and juvenile ecology of the temperate octocoral Alcyonium siderium Verrill. 2. Fecundity, survival, and juvenile growth. Journal of Experimental Marine Biology and Ecology 72:263-285.

Shlesinger Y, Goulet TL, and Loya Y. 1998. Reproductive patterns of scleractinian corals in the northern Red Sea. Marine Biology 132:691-701.

Simpson CJ. 1985. Mass spawning of scleractinian corals in the Dampier Archipelago and the implications for management of coral reefs in Western Australia. Perth, Western Australia: Department of Conservation and Environment p35.

Smith LD, Devlin M, Haynes D, and Gilmour JP. 2005. A demographic approach to monitoring the health of coral reefs. Marine Pollution Bulletin 51:399-407.

Speed CW, Babcock RC, Bancroft KP, Beckley LE, Bellchambers LM, Depczynski M, Field SN, Friedman KJ, Gilmour JP, and Hobbs J-PA. 2013. Dynamic Stability of Coral Reefs on the West Australian Coast. Plos one 8:e69863.

Stobart B, Babcock RC, and Willis BL. 1992. Biannual spawning of three species of scleractinian coral from the Great Barrier Reef. Proceedings of the Seventh International Coral Reef Symposium, Guam 494-499.

Stoddart C, Stoddart J, and Blakeway D. 2012. Summer spawning of Porites lutea from northwestern Australia. Coral Reefs 31:787-792.

Stoddart JA. 1983. Asexual reproduction of planulae in the coral Pocillopora damicornis. Marine Biology 76:279-284.

Stoddart JA. 1984. Genetic differentiation amongst populations of the coral Pocillopora damicornis off southwestern Australia. Coral Reefs 3:149-156.

Stoddart JA, and Black R. 1985. Cycles of gametogenesis and planulation in the coral Pocillopora damicornis. Marine Ecology Progress Series 23:153-164.

Styan CA, and Rosser NL. 2012. Is monitoring for mass spawning events in coral assemblages in north Western Australia likely to detect spawning? Marine Pollution Bulletin. 
1389 Szmant-Froelich A, Reutter M, and Riggs L. 1985. Sexual reproduction of Favia fragum (Esper):

1390

1391

1392

1393

1394

1395

1396

1397

1398

1399

1400

1401

1402

1403

1404

1405

1406

1407

1408

1409

1410

1411

1412

1413

1414

1415

1416

1417

1418

Lunar patterns of gametogenesis, embryogenesis and planulation in Puerto Rico. Bulletin of Marine Science 37:880-892.

Szmant AM, and Gassman NJ. 1990. The effects of prolonged "bleaching" on the tissue biomass and reproduction of the reef coral Montastrea annularis. Coral Reefs 8:217-224.

Tanner JE. 1996. Seasonality and lunar periodicity in the reproduction of Pocilloporid corals. Coral Reefs 15:59-66.

Thomson D, and Frisch A. 2010. Extraordinarily high coral cover on a nearshore, high-latitude reef in south-west Australia. Coral Reefs 29:923-927.

van Oppen M, Willis BL, Van Rheede T, and Miller DJ. 2002. Spawning times, reproductive compatabilities and genetic structuring in the Acopora aspera group; evidence for natural hybridization and semi-permeable species boundaries in corals. Molecular Ecology 11:1363-1376.

van Woesik R. 2010. Calm before the spawn: global coral spawning patterns are explained by regional wind fields. Proceedings of the Royal Society B-Biological Sciences 277:715722.

Vargas-Ãngel B, Colley SB, Hoke SM, and Thomas JD. 2006. The reproductive seasonality and gametogenic cycle of Acropora cervicornis off Broward County, Florida, USA. Coral Reefs 25:110-122.

Veron J. 2011. Coral taxonomy and evolution. In: Z D, and N S, editors. Coral reefs: an ecosystem in transition. Springer Netherlands. p 37-45.

Veron JEN. 1993. Hermatypic corals of Ashmore Reef and Cartier Island. In: Berry PF, ed. Marine Faunal Surveys of Ashmore Reef and Cartier Island North-Western Australia. Perth.: Records of the Western Australian Museum 13-14.

Veron JEN, and Marsh LM. 1988. Hermatypic corals of Western Australia. Records of the Western Australian Museum. ed. Perth, Western Australia. p 1-136.

Wallace CC. 1985. Reproduction, recruitment and fragmentation in nine sympatric species of the coral genus Acropora. Marine Biology 88:217-233.

Wallace CC. 1999. Staghorn corals of the world : a revision of the coral genus Acropora. Collingwood, Vic.: CSIRO Publishing. 
1419 Wallace CC, Chen CA, Fukami H, and Muir PR. 2007. Recognition of separate genera within

1420

1421

1422

1423

1424

1425

1426

1427

1428

1429

1430

1431

1432

1433

1434

1435

1436

1437

1438

1439

1440

1441

1442

1443

1444

1445

1446

1447

1448

1449

Acropora based on new morphological, reproductive and genetic evidence from Acropora togianensis, and elevation of the subgenus Isopora Studer, 1878 to genus (Scleratinia: Astrocoeniidae; Acroporidae). Coral Reefs 26:231-239.

Ward S, Harrison P, and Hoegh-Guldberg O. 2000. Coral bleaching reduces reproduction of scleractinian corals and increases susceptibility to future stress. Proceedings of the Ninth International Coral Reef Symposium, Bali 2:1123-1128.

Wells FE, Rose R, and Lang S. 1985. An analysis of benthic marine invertebrate communities in subtidal seagrass and sand habitats in Shark Bay, Western Australia. Records of the Western Australian Museum 12:47-56.

Wells FE, and Walker DI. 1993. Introduction to the marine environment of Rottnest Island, Western Australia. The Marine Flora and Fauna of Rottnest Island, Western Australia: Western Australian Museum.

Willis BL. 1985. Phenotypic plasticity versus phenotypic stability in the reef corals Turbinaria mesenterina and Pavona cactus. 5th International Coral Reef Congress. p 107-112.

Willis BL. 1987. Morphological variation in the reef corals Turbinaria mesenterina and Pavona cactus: synthesis of transplant, histocompatibility electrophoresis, growth and reproduction studies. James Cook University.

Willis BL. 1990. Species concepts in extant scleractinian corals: considerations based on reproductive biology and genotypic population structures. Systematic Botany 15:136-149.

Willis BL, Babcock RC, Harrison PL, and Oliver JK. 1985. Patterns in the mass spawning of corals on the Great Barrier Reef from 1981 to 1984. Proceedings of the Fifth International Coral Reef Congress, Tahiti:343-348.

Willis BL, van Oppen MJH, Miller DJ, Vollmer SV, and Ayre DJ. 2006. The role of hybridization in the evolution of reef corals. Annual Review of Ecology, Evolution and Systematics 37:489-517.

Wilson B. 2013. The Biogeography of the Australian North West Shelf: Environmental Change and Life's Response: Elsevier.

Wilson JR, and Harrison PL. 2003. Spawning patterns of scleractinian corals at the Solitary Islands - a high latitude coral community in eastern Australia. Marine Ecology Progress Series 260:115-123.

Peer] reviewing PDF | (2016:02:9241:1:0:NEW 12 Apr 2016) 
1450 Wolstenholme JK. 2004. Temporal reproductive isolation and gametic compatibility are

1451 evolutionary mechanisms in the Acropora humulis species group (Cnidaria; Scleractinia).

1452 Marine Biology 144:567-582.

1453

1454 